\title{
Central place foragers and moving stimuli: a hidden-state model to discriminate the processes affecting movement
}

\author{
Enrico Pirotta $^{1 *}$, Ewan W. J. Edwards ${ }^{2,3}$, Leslie New ${ }^{1}$, Paul M. Thompson ${ }^{2}$
}

${ }^{1}$ Department of Mathematics and Statistics, Washington State University, Vancouver, WA, USA

${ }^{2}$ Lighthouse Field Station, University of Aberdeen, Cromarty, Scotland, UK

${ }^{3}$ Marine Scotland Science, The Scottish Government, Aberdeen, Scotland, UK

*Corresponding author: enrico.pirotta@wsu.edu

Running headline: Central place foragers’ movement towards attractors. 


\section{Abstract}

1. Human activities can influence the movement of organisms, either repelling or attracting individuals depending on whether they interfere with natural behavioural patterns or enhance access to food. To discern the processes affecting such interactions, an appropriate analytical approach must reflect the motivations driving behavioural decisions at multiple scales.

2. In this study, we developed a modelling framework for the analysis of foraging trips by central place foragers. By recognising the distinction between movement phases at a larger scale and movement steps at a finer scale, our model can identify periods when animals are actively following moving attractors in their landscape.

3. We applied the framework to GPS tracking data of northern fulmars Fulmarus glacialis, paired with contemporaneous fishing boat locations, to quantify the putative scavenging activity of these seabirds on discarded fish and offal. We estimated the rate and scale of interaction between individual birds and fishing boats and the interplay with other aspects of a foraging trip.

4. The model classified periods when birds were heading out to sea, returning towards the colony or following the closest boat. The probability of switching towards a boat declined with distance and varied depending on the phase of the trip. The maximum distance at which a bird switched towards the closest boat was estimated around $35 \mathrm{~km}$, suggesting the use of olfactory information to locate food. Individuals spent a quarter of a foraging trip, on average, following fishing boats, with marked heterogeneity among trips and individuals.

5. Our approach can be used to characterise interactions between central place foragers and different anthropogenic or natural stimuli. The model identifies the processes influencing central place foraging at multiple scales, which can improve our understanding of the 
mechanisms underlying movement behaviour and characterise individual variation in interactions with a range of human activities that may attract or repel these species.

Therefore, it can be adapted to explore the movement of other species that are subject to multiple dynamic drivers.

Keywords: Animal telemetry, Bayesian, movement attractors, central place foraging, Fulmarus glacialis, hidden state modelling, multi-scale.

\section{Introduction}

Animal movements may change in response to various human activities operating in their environment. These may have a repelling or an attracting effect on wildlife depending on whether they interfere with natural behavioural patterns or enhance access of food (Bartumeus et al. 2010; Hays et al. 2016). Aspects of these interactions that are particularly relevant to inform management include the scale at which they occur, the prevalence among individuals and their interplay with other biological and ecological functions (Crowder \& Norse 2008).

Assessing the movement of free-ranging animals towards or away from particular centres of attraction in their landscape is challenging. An animal's decision to head towards attractors depends on a series of contextual factors, including the individual's body condition, reproductive needs, previous experience, current activity and underlying motivation at a given time and over a longer time scale (Nathan et al. 2008; McClintock et al. 2012; Michelot et al. 2017). The assessment is further complicated when these attractors move, because their continuously varying distance from an animal will impact the individual's ability to sense their presence and, when within detectable distance, will be traded-off against the potential benefit they represent 
(Bodey et al. 2014). Understanding this complex decision-making thus requires discriminating among the different processes that influence how and why the animals move at different scales (Nathan et al. 2008) and disentangling their interaction with new attracting components entering the landscape.

Many species act as central place foragers (Orians \& Pearson 1979), including seabirds and pinnipeds (Boyd et al. 2014; Patrick et al. 2014). These animals exploit food resources around a particular location to which they are bound to return, often due to reproductive requirements (Stephens, Brown \& Ydenberg 2007). Particularly in the early phases of their life, young depend on parents for food and protection, and adults are constrained to perform regular return trips to the colony, den or nest. When they encounter profitable patches along these trips, their fine-scale movement changes, often becoming slower and more convoluted (Michelot et al. 2017). This behavioural mode is known as area-restricted search (ARS) and is believed to reflect foraging activity in a patchy landscape (Kareiva \& Odell 1987). Therefore, characterising the interaction of central place foragers with human activities and other moving attractors in the environment needs to account for the interplay of the various attracting processes and multi-scale drivers of movement.

Hidden state models are routinely applied to animal telemetry data with the aim of identifying periods during which an individual is travelling through unprofitable areas (transit mode) and periods spent searching for food in profitable patches (resident or ARS mode) (Patterson et al. 2008; McClintock et al. 2012; Beyer et al. 2013; Jonsen et al. 2013). The two modes can be distinguished based on the movement features estimated from the track, whereby transit mode is faster and more directed and resident mode is slower and more convoluted (Jonsen et al. 2013). However, in addition to fine-scale step lengths and turning decisions (i.e. the movement steps) 
that define the current behavioural mode, an individual's movement will also be influenced by a broader attraction process that determines its movement phase (Nathan et al. 2008). Particularly, central place foragers will first depart from the home base (hereafter central place), heading out towards available foraging patches, and, after having spent some time travelling and foraging, will return towards the central place (Michelot et al. 2017). The overall bearing during different phases of a trip (e.g. heading away from or towards the central place) can be decoupled from the process determining transit versus resident behaviour, in that an animal might engage in either of the two modes irrespective of where it is broadly heading. As a result, two state processes can be thought as occurring concomitantly. First, a larger-scale process determining the overall bearing of the animal as the trip progresses, reflecting the different phases of the trip. Second, a finerscale process affecting the animal's residency in a given area, reflecting the movement mode at any moment in time (Nathan et al. 2008). Failing to distinguish the two may confound the estimation of the state-specific parameters and, ultimately, the identification of the corresponding states.

In this study, we developed a modelling framework for the analysis of the movements of central place foragers, where the process affecting an animal's bearing was treated separately from the process affecting its residency in an area. We illustrate this approach using a case study that explores how seabird movements are influenced by the presence of fishing boats. Discarding by commercial fisheries has been recognised as one of the key challenges to achieving the sustainable use of marine resources (Kelleher 2005). Species, populations and individuals differ in their reliance on discards (e.g. Phillips et al. 1999; Votier et al. 2004, 2010; Tew Kai et al. 2013; Granadeiro, Brickle \& Catry 2014; Bodey et al. 2014; Patrick et al. 2015). The fine-scale analysis of seabird movement behaviour in relation to fishing boats can reveal whether birds are 
actively following the boats and permit quantification of key features of these interactions, e.g. the scale, frequency and individual heterogeneity (Votier et al. 2010; Bodey et al. 2014; Patrick et al. 2015; Collet, Patrick \& Weimerskirch 2017a; b). Developing a modelling framework to evaluate the dependency of individual seabirds on discards is therefore critical for evaluating demographic effects and the potential consequences that changes in international regulation may have on marine food webs (Votier et al. 2004; Bicknell et al. 2013; Tew Kai et al. 2013; Cohen et al. 2014).

By recognising the distinction between movement steps at a finer scale and movement phases at a larger scale, our model can identify periods when an animal is actively following a fishing boat, irrespective of its movement mode. We apply the framework to GPS data collected on a central place forager, the northern fulmar Fulmarus glacialis (hereafter 'fulmar'), paired with anonymised locations of fishing boats operating contemporaneously to the tracking data. Fulmars are known to feed on a variety of prey, including offal and non-target fish discharged by commercial fisheries (Phillips et al. 1999) and are therefore one of the species expected to interact with fishing boats to at least some extent. We illustrate how this modelling framework can be used to estimate the rate of interaction between individual animals and moving attractors in their environment, the scale at which these interactions occur and their interplay with other aspects of a foraging trip, such as foraging activity or the need to return to the central place.

\section{Materials and methods}

\section{Model structure}

We developed a modelling framework for the foraging trips of central place foragers where movement phase and movement steps were treated as separate, hidden states (Nathan et al. 2008) 
(Fig. 1). We assumed that a first hidden state variable, $s_{i, t}$, defined the mean bearing of the animal at each time step $t$ of trip $i$, while a second hidden state variable, $r_{i, t}$, affected the step length and the variability around the mean bearing (Table S1). Under the first state process, an individual could be heading either away from the central place $\left(s_{i, t}=1\right)$, towards the central place $\left(s_{i, t}=2\right)$ or towards the closest moving attractor $\left(s_{i, t}=3\right)$. When the animal was moving away from the central place, we assumed that the state-specific mean bearing $\mu_{s, i, t}$ was drawn from a wrapped Cauchy distribution centred on the angle $v_{i}$ between the central place and the furthest location reached during trip $i$, with unknown trip-specific concentration parameter $\varepsilon_{i}$, i.e. $\mu_{1, i, t} \sim w C\left(v_{i}, \varepsilon_{i}\right)$. If the animal was moving towards the central place, it moved with mean bearing $\mu_{2, i, t}$, which was the angle between the current location and the central place. Finally, if the animal was moving towards the closest attractor, the mean bearing $\mu_{3, i, t}$ represented the angle between the current location and that attractor. The mean bearing under state $s_{i, t}=1$ was not fixed because preliminary exploration of the available data showed that the degree of directedness when moving away from the central place could vary among different trips (Fig. 2). Taken together, this made it possible to distinguish the two processes affecting angle concentration; that is, an individual's current behavioural mode and the variation in directedness among different trips. However, when running a model with fixed bearing for state 1, all other estimates were largely unchanged (Table S9). We assumed that, in the first time step of a trip, an individual was moving away from the central place $\left(s_{i, 1}=1\right)$.

Under the second state process, an individual could be in transit $\left(r_{i, t}=1\right)$ or resident mode $\left(r_{i, t}=\right.$ 2). Following Morales et al. (2004) and McClintock et al. (2012, 2013), the step length at time $t$ of trip $i, x_{i, t}$, was assumed to emerge from a Weibull distribution with state-specific scale $\left(\alpha_{r}\right)$ and shape $\left(\beta_{r}\right)$ parameters, i.e. $x_{i, t} \sim W\left(\beta_{r}, \alpha_{r}\right)$, and steps in transit mode were assumed to be larger 
than steps in resident mode, i.e. $\alpha_{1}>\alpha_{2}$. The movement mode also affected the concentration parameter of the bearing distribution $\rho_{r}$, and transit mode was assumed to be more directed than resident mode, i.e. $\rho_{1}>\rho_{2}$. We assumed that, in the first time step, an individual leaving the central place was in transit mode $\left(r_{i, 1}=1\right)$. The two state processes in combination affected the observed bearing $\theta_{i, t}$, which emerged from a wrapped Cauchy distribution (Morales et al. 2004; McClintock et al. 2012, 2013) with mean $\mu_{s, i, t}$ and concentration parameter $\rho_{r}$, i.e. $\theta_{i, t} \sim w C\left(\mu_{s, i, t}\right.$, $\rho_{r}$ ). Other distributions could alternatively be used to model step lengths and bearings (Beyer et al. 2013; Michelot, Langrock \& Patterson 2016; Michelot et al. 2017). To assess whether the choice of such distributions affected the results, we ran an alternative version of the model that used a von Mises distribution for the animal's bearing at each time step and a Gamma distribution for its step length (detailed in Appendix S4).

The first state process was also informed by the observed distance, $d_{i, t}$, between an individual and the closest attractor, which had state-dependent lognormal distribution $d_{i, t} \sim \log N\left(\varphi_{s}, \sigma_{s}\right)$. This distribution was chosen to account for the fact that distance values can only be positive and their distribution will thus tend to be rightly skewed (Fig. S1). Specifically, under state $s_{i, t}=1$ and $s_{i, t}$ $=2$ (i.e. when not moving towards an attractor), distance from the closest attractor was expected to have the same statistical distribution, but be larger and more variable than under state 3 on average, i.e. $\varphi_{1}=\varphi_{2}>\varphi_{3}$ and $\sigma_{1}=\sigma_{2}>\sigma_{3}$.

The temporal sequences of both hidden states were treated as Markov processes (i.e. the state at a moment in time only depended on the previous state), regulated by two separate sets of transition probabilities among states (Fig. 1). The transition probabilities for the first process constituted a $3 \times 3$ matrix $\Gamma$, where each element, $\gamma_{h, j}$, indicated the probability that $s_{i, t}=j$ given that $s_{i, t-1}=h$. Because the chance of an individual moving towards the central place increases as time 
progresses, the transition probabilities towards state 2 (i.e. heading towards the central place) were assumed to depend on the elapsed proportion $p_{i, t}$ of the total trip. Similarly, the transition probabilities towards state 3 (i.e. heading towards the closest attractor) were assumed to depend on the distance to the closest attractor, $d_{i, t}$. To model these effects, a multinomial logit formulation was used. Specifically, the transition probabilities to state 2 at time $t$ of trip $i$ were modelled as $\operatorname{logit}\left(\gamma_{h, 2, i, t}\right)=a_{h, 2}+b_{h, 2} \cdot p_{i, t}$, where $s_{i, t-1}=h, a_{h, 2}$ is the basal probability of transitioning from state $h$ to state 2 on the logit scale and $b_{h, 2}$ represents the effect of the elapsed proportion of the trip. The transition probabilities to state 3 at time step $t$ of trip $i$ were formulated as $\operatorname{logit}\left(\gamma_{h, 3, i, t}\right)=a_{h, 3}+b_{h, 3} \cdot d_{i, t}$, where $s_{i, t-1}=h, a_{h, 3}$ is the basal probability of transitioning from state $h$ to state 3 on the logit scale, and $b_{h, 3}$ is the effect of the distance of the closest attractor. Transition probabilities to state 1 were then derived as $\gamma_{h, 1, i, t}=1-\gamma_{h, 2, i, t}-\gamma_{h, 3, i, t}$. The transition probabilities for the second process formed a $2 \times 2$ matrix $\Delta$, where each element, $\delta_{k, l}$, was the probability that $r_{i, t}=l$ given that $r_{i, t-1}=k$.

We use a formulation similar to McClintock et al. (2013) to express the joint conditional likelihood ( $f$ ) of all observations (step lengths $\mathbf{x}$, turning angles $\boldsymbol{\theta}$, distances from the closest attractor $\mathbf{d}$ ) and unknown state sequences (s and $\mathbf{r}$ ) as the product of their independent likelihoods:

$f(\mathbf{x}, \boldsymbol{\theta}, \mathbf{d}, \mathbf{s}, \mathbf{r} \mid \boldsymbol{\omega})=\prod_{i=1}^{I} \prod_{t=2}^{T_{i}}\left[f\left(x_{i, t} \mid \boldsymbol{\omega}, r_{i, t}\right) \cdot f\left(\theta_{i, t} \mid \boldsymbol{\omega}, s_{i, t}, r_{i, t}\right) \cdot f\left(d_{i, t} \mid \boldsymbol{\omega}, s_{i, t}\right) \cdot\right.$ $\left.f\left(s_{i, t} \mid \boldsymbol{\omega}, s_{i, t-1}\right) \cdot f\left(r_{i, t} \mid \boldsymbol{\omega}, r_{i, t-1}\right)\right]$, where $\boldsymbol{\omega}$ denotes the set of all model parameters, $I$ is the total number of trips and $T_{i}$ is the duration of each trip. 


\section{Case study: data collection and processing}

We used fulmar tracking data collected on Eynhallow, Scotland $\left(59.12^{\circ} \mathrm{N}, 3.1^{\circ} \mathrm{W}\right.$; Fig. 2) as part of a long-term demographic study (Thompson \& Ollason 2001) to demonstrate the application of the analytical approach. All bird handling, marking and telemetry tagging was carried out under Home Office and British Trust for Ornithology licenses. Adult fulmars were caught on the nest during early chick rearing between the 12th and the 17th of July 2009 using a net or noose. A GPS logger (iGot-U GT-120, MobileAction ${ }^{\circledR}$, Taipei, Taiwan; 18 g) was attached to mantle feathers using tape (Tesa ${ }^{\circledR} 4651$, Hamburg, Germany). GPS devices were set to record one position every 10 minutes. Tagged birds were recaptured after one or multiple foraging trips, and location data were downloaded using the manufacturer’s software.

Under EC Regulation No. 2244/2003 and Scottish Statutory Instrument (SI) 392/2004 the geographical position, identity, course and speed of all fishing boats above a given size (15 m in 2009) must be reported at least every two hours. Satellite tracking via vessel monitoring system (VMS) is used to record such information (Witt \& Godley 2007). Anonymised VMS locations of fishing boats operating concurrently to fulmar GPS deployments in July 2009 were provided by Marine Scotland Science. Only VMS locations associated with fulmar data were analysed, making it impossible to identify specific boats from our data and results.

Hidden state models require data collected at regular time intervals. Therefore, fulmar tracks were linearly interpolated at a 10-minute resolution using package adehabitatLT (Calenge 2006) in R (R Development Core Team 2016). Ninety-four percent of the observed intervals between consecutive bird GPS positions were shorter than the chosen time step, ensuring limited interpolation over long unobserved periods. The step length, i.e. the distance between consecutive locations in degrees, and the bearing, i.e. the absolute angle of each step measured 
from 0 radians, were calculated for each location. VMS data were also linearly interpolated at the same temporal resolution to match fulmar data. Regardless of their distance from a bird, all boats occurring within a 5-minute time window around a fulmar's 10-minute fix were identified. The coordinates and distance in kilometres of the closest boat were associated to the corresponding fulmar location.

Our analysis aimed to classify fulmar behaviour within a foraging trip. Therefore, a bird's movements in inshore waters around the colony were excluded. Moreover, only one individual was tracked over two different foraging trips, so these were treated separately in the analysis. The overall bearing of each trip was calculated as the angle between the starting location and the location furthest from the colony reached during that trip.

Because the resolution of fishing boat data was relatively coarse (mean interval between VMS locations: $110 \mathrm{~min}$; standard deviation: $91 \mathrm{~min}$ ), their interpolation at the same temporal scale of fulmar GPS tracks introduced an unknown degree of error over periods between consecutive VMS locations. We tested whether such uncertainty affected the conclusions drawn from our model, using the approach developed by Torres et al. (2011) to generate circular spatial buffers encompassing the area where a boat could have been at each unobserved time step. We developed a modified version of the model that accounted for the resulting uncertainty in angle and distance to the closest boat, as described in detail in Appendix S3.

\section{Model fitting}

Models were fitted in a Bayesian framework using OpenBUGS run from R (package R2OpenBUGS; Sturtz, Ligges \& Gelman 2005). A Bayesian approach was chosen because of its flexibility, which allows concomitantly fitting multiple state processes affecting different 
components of behaviour. This implementation also facilitates potential extensions to include a hierarchical structure (see Discussion). Prior distributions for model parameters are listed in Table S2 in Supporting Information. Markov chain Monte Carlo (MCMC) algorithms were iterated until convergence of the states and parameters. Three chains were run in parallel, each starting at different initial values. The proportions $\lambda_{1,1-3}$ and $\lambda_{2,1-2}$ of time steps classified under each state were used to monitor the convergence of both state variables. Convergence was assessed by visually inspecting trace and density plots (Lunn et al. 2013), and confirmed using the Brooks-Gelman-Rubin (BGR) diagnostic and Monte Carlo (MC) error (Lunn et al. 2013). The package coda was used to assess convergence, calculate effective sample size and extract posterior estimates (Plummer et al. 2006). Appendix S1 reports the code for the model in OpenBUGS format.

\section{Results}

Six individual fulmars were tagged during the study period, with a total of 7 foraging trips available for analysis (Fig. 2). Trips lasted 25 hours on average (range 18 - 34 hours). The final, regularised and filtered dataset included 1,061 locations. The median distance from the closest boat at any moment in time was $18 \mathrm{~km}$, although this ranged widely (between 70 meters and 57 $\mathrm{km}$ ) and appeared to have a multimodal distribution (Fig. S1).

The initial 10,000 iterations were discarded as burn-in, while 200,000 unthinned iterations were used for inference (Link \& Eaton 2012). The analysis required $18 \mathrm{~h}$ (including model compiling and initialisation times) on 8 Intel(R) Core(TM) i7-4910MQ CPU @ 2.90GHz processors, 16 GB RAM. For comparison, fitting the model to a subset of the data including four trips and 
approximately half of the data points (582 locations) required $8.5 \mathrm{~h}$. Convergence was confirmed by the relative diagnostics and the effective sample size was greater than 400 for all parameters (Lunn et al. 2013). Despite the large number of parameters in the model, these all converged adequately and were estimated with precision, possibly because a Bayesian approach allowed setting some broad constraints on the priors that facilitated mixing and state identification (Table S2). For example, we set state $r_{i, t}=2$ to be more convoluted than $r_{i, t}=1$ by specifying a constraint on angle concentration $\rho_{1}>\rho_{2}$. We also set $\rho_{1} \geq 0.5$ so that $r_{i, t}=1$ represented directed movement. Similar constraints reflected a broad understanding of the biological processes underlying the data. However, some of the trip-specific concentration parameters for the bearing of state 2 (heading out to sea), $\varepsilon_{i}$, showed relatively poorer chain mixing because movements tended to be highly directed during some portions of these trips (i.e. $\varepsilon_{i}$ close to 1; Fig. S2). Due to computing memory limitations, we retained only one in 20 iterations for both state variables. Posterior estimates of model parameters and associated uncertainty are summarised in Table S3.

The model correctly classified the periods when a bird was heading out to sea and moving towards the colony (Fig. 3a), which were characterised by a lognormal distribution of distances from the closest boat centred on $3.1 \mathrm{~km}$ on the log scale (i.e. $22 \mathrm{~km}$ ). In contrast, when a bird was following the closest boat, the mean distance was smaller $(0.9 \mathrm{~km}$ on the log scale, i.e. 2.5 km). The probability of heading towards the colony increased as the trip progressed (Fig. 4a), while the probability of switching towards a boat declined as the distance from the closest boat increased (Fig. 4b). Specifically, the probability of a bird switching towards a boat if it was travelling towards the colony (state 2) approached 0 after $30 \mathrm{~km}$, while in state 1 (when the bird was heading out to sea) the transition probability approached 0 before $20 \mathrm{~km}$. The relationship with distance was also more variable in state 2 than under state 1 . When heading towards a boat, 
an individual tended to remain in that state with high probability, up to a distance of more than $30 \mathrm{~km}$. Animations of the tracks coloured by the median posterior estimate of state $s_{i, t}$ at each time step (particularly for trip 3, 4 and 7) illustrate the ability of the model to identify periods when a bird was actively following the closest fishing boat (Appendix S2; examples in Fig. 5).

The distinction between transit and resident mode (state $r_{i, t}$ ) was also clear, with resident mode being characterised by small, convoluted steps $\left(\rho_{2}=0.37\right.$, while $\left.\rho_{1}=0.81\right)$ (Fig. 3b). When an individual was heading out to sea, $43 \%$ of locations were in transit mode, against $57 \%$ in resident mode (Table S4). Transit mode became more frequent while travelling towards the colony, representing $59 \%$ of locations in transit mode against $41 \%$ in resident mode. When following a boat, birds were mostly (76\%) in resident mode, although in $24 \%$ of the time they showed directed movement with larger step lengths, corresponding to the initial approach phase (Table S4). On average, birds spent $24 \%$ of their time following fishing boats, but with marked differences among trips and individuals (Table S5). Boat interactions lasted between 10 minutes and 7.3 hours (mean $=2.7$ hours; SD $=2.1$ ). 33\% of ARS behaviour occurred while following a boat, while the remaining $67 \%$ occurred while heading out to sea or towards the colony.

Results remained largely unchanged if a different set of distributions for the step length and bearing was used (Appendix S4). Similarly, the inclusion of uncertainty in boat interpolated locations following Torres et al. (2011) did not alter the conclusions of the model (Appendix S3). 


\section{Discussion}

The modelling approach presented in this study allows the identification of the processes that regulate the movement of central place foragers over the course of a foraging trip. These processes operate at different scales and result in heterogeneous movement steps (defining an individual's behavioural mode) nested within the broader phases that constitute a foraging trip. Therefore, the model explicitly acknowledges the multi-scale nature of animal movement ecology, reflecting aspects of the short- and long-term motivation driving an individual's behavioural decisions as it moves in the environment (Nathan et al. 2008). Here, the approach was applied to classify periods when a marine central place forager, the northern fulmar, was actively following fishing boats, presumably to access offal and non-target fish discarded in the sea. More generally, this approach offers the potential to explore how various ecological agents and anthropogenic activities could influence movement patterns by either attracting or repelling individuals as they forage from their central place.

Discriminating the three attraction processes defining the movement phase of a foraging trip (away from the central place, towards the central place and towards moving attractors) was possible because these were explicitly decoupled from the process determining movement features at a small scale (i.e. the speed and directedness of movement steps). Therefore, movement mode and phase can be combined flexibly via the two hidden state processes. Our model differs from the approach proposed by Michelot et al. (2017), who defined movement phases in conjunction with specific features of the associated steps. Their approach is effective when a foraging trip can be split into predefined segments. However, it could not accommodate scenarios where foraging areas are less localised, the interaction with attractors in the landscape occurs at irregular times and locations, and the attractors may move. The novel formulation 
presented here offers a general approach that does not require one to assume a stereotypical sequence of states during a trip, and further extends the framework proposed by McClintock et al. (2012) for biased movements. For example, in trip number 6 of this study, the tracked bird moved towards the colony, but then flew out again before returning to the colony and concluding the trip, a sequence of behaviours that was correctly classified by the model. Similarly, foraging bouts indicated by the ARS mode were not constrained to occur in predefined foraging areas. To our knowledge, this is the first example of telemetry data being used to model multiple state processes separately at different scales. Overlaying the two state processes highlighted that ARS behaviour occurred disproportionately in different phases of the trip. This mode corresponds to putative foraging activity (Kareiva \& Odell 1987), but possibly also includes resting and drifting on the sea surface. Understanding how movement modes are distributed over the course of a foraging trip is important to characterise the dynamic allocation of time and energy to different activities (Grémillet et al. 2003). This could shed light on an individual’s decision-making process, as well as provide information on the variable vulnerability to anthropogenic threats and disturbances at different moments in time (Dean et al. 2013). For species that only forage in well-defined regions (Michelot et al. 2017), the approach could be modified to explicitly quantify the increased probability of switching to ARS mode as time or distance from the central place increases. Moreover, a fourth state could be added to the first state process to further distinguish movement that is not directed towards attractors or the central place into movement away from the central place and movement with unknown bearing (e.g. targeting foraging patches off the main course of the trip). We ran a model with this additional state and present results in the Supplementary Information (Appendix S5, Table S8 and Fig. S5). Overall, movement states under the two processes could be successfully described because of the high 
degree of separation between the corresponding distributions of the movement variables and the use of the ancillary variable distance from the closest attractor (Beyer et al. 2013).

We focused on seabirds' attraction to fisheries as an example of the relevance of the proposed approach to inform management of human activities at sea. Seabirds are known to occur in areas that are intensely used by fisheries, but it is often unclear whether the animals are directly exploiting fishery discards or relying on the same prey aggregations (Karpouzi, Watson \& Pauly 2007; Tew Kai et al. 2013). Our analytical approach can be used to assess whether tracked animals changed their movement patterns and actively followed fishing boats. Because the movement mode is decoupled from the attraction towards a boat, the model both identifies the threshold distance at which an individual starts its approach and estimates the time spent putatively foraging around a boat. We applied the model to fulmar tracking data and found that, on average, tracked birds spent around a quarter of their trips in close proximity to fishing boats, with one bird actively following a boat for $>7$ hours. Moreover, a third of recorded ARS behaviour occurred while following a boat, suggesting that a substantial component of these birds' foraging activity could be dependent on discards. However, the time spent tracking boats varied widely among individuals and trips. Such variability could be ascribed to the differential occurrence of fishing boats within the detection range of an individual during a specific trip, but could also reflect individual differences in the propensity to approach boats and in the reliance on discards as a source of food (Votier et al. 2010; Granadeiro et al. 2014; Patrick et al. 2015). In turn, these individual differences in interaction rate could result in different exposure to bycatch risk (Lewison et al. 2014). In future, multiple trips by single individuals could be used to characterise such heterogeneity, paired with stable isotope analysis to verify resulting dietary differences (Votier et al. 2010; Granadeiro et al. 2014). To this purpose, the Bayesian 
formulation of the model will grant the flexibility required to include a hierarchical structure and accommodate individual random effects. With a larger tracking dataset, our model could also be extended to include age, sex, season and time of day as covariates potentially affecting transition probabilities among states, which could help clarify some of the observed differences among individuals (Collet et al. 2017b). The effects of a variable reliance on discards and by-catch risk on individual condition, survival and reproductive success could then be evaluated using life history data collected via long-term population monitoring (Cohen et al. 2014; Collet et al. 2017b).

The ability of the model to capture the interplay of motivations driving individual decisions was demonstrated in this study with the inclusion of the effects of distance from the closest boat and proportion of the trip elapsed. The state-specific probability of switching towards the closest boat and its variable relationship with distance highlights the trade-offs an individual makes between the potential benefits of accessing discards, the distance to reach this source of food and the phase of the trip (Cohen et al. 2014). While travelling out to sea in the initial part of a foraging trip, fulmar propensity to switch towards a boat tapered off rapidly with distance, reaching 0 at around $20 \mathrm{~km}$. In this phase, variability among individuals and trips was small. In contrast, the propensity to switch towards a boat when travelling back to the colony may be balanced against several other factors, such as the cumulative feeding success over the trip and the growing pressure to return to attend the chick. This could explain the estimated larger variability in the corresponding transition probability. An individual may also be more willing to travel long distances to reach a boat if a trip was particularly unsuccessful (Cohen et al. 2014), which would justify the probability of following a boat dropping to 0 at larger distances. Similarly, when a bird switched its movement towards a boat, it was unlikely to switch states, reflecting a relatively 
stable decision-making process. In general, the maximum ecological footprint of fishing boats’ influence on birds' decisions was over three times greater for fulmars than previously estimated for northern gannets Morus bassanus (Bodey et al. 2014). Here, we estimated that a boat could attract a fulmar up to approximately $35 \mathrm{~km}$, which could represent the maximum detection range for the species. This distance is comparable to the $30 \mathrm{~km}$ threshold identified by Collet, Patrick \& Weimerskirch (2017b) for wandering albatrosses Diomedea exulans and black-browed albatrosses Thalassarche melanophrys. The inconsistency among species could reflect differences in the sensory system used to locate food, with Procellariiformes such as fulmars and albatrosses relying largely on olfaction as opposed to sight (Hutchison \& Wenzel 1980; Nevitt 2008). Further work applying this modelling approach to other scavengers could quantify species- or population-specific parameters, which would support the investigation of the implications of discarding for different seabird communities.

Fishing boat locations were only available from VMS at a coarser temporal resolution than fulmar GPS tracks. Therefore, an unknown degree of uncertainty surrounds our interpolated boat locations. However, it is important to note that our approach detected direct interactions between birds and fishing boats despite such uncertainty, and that the estimated scale and frequency of interactions between tracked birds and fishing boats did not vary when the method proposed by Torres et al. (2011) was used to capture the potential magnitude of interpolation errors. In addition, boat locations were not filtered on the basis of their activity state, which previous studies have inferred from the boats' movement patterns (e.g. Bodey et al. 2014). We did not take this approach because we did not want to assume a priori that birds only follow boats when the vessels are actively fishing. Collet et al. (2017a) did not find a relationship between attendance to fishing boats and mass gain, suggesting that attraction might occur even in the 
absence of active fishing or discarding. Future work could explore the potential difference in attractiveness among different activities and types of fishing boats (e.g. trawling versus nontrawling), which also contribute to the trade-offs regulating behavioural decisions, thus shedding light on some of the heterogeneity among trips we detected.

The model developed here has broad applicability beyond the presented case study of seabird interactions with fisheries. Firstly, it could naturally be applied to quantify the attraction of other central place foraging species towards any static or mobile anthropogenic activity providing enhanced access to food, e.g. pinnipeds targeting underwater structures acting as reefs (Russell et al. 2014) or fish farms (Sepúlveda et al. 2015). The approach could also be modified to model individuals' avoidance of disturbing activities, such as intense noise sources (e.g. Russell et al. 2016). In addition, the role of dynamic environmental variables on movement decisions could be explored. For example, the characterisation of the first phase of seabirds' foraging trips could be improved by including an effect of wind direction in determining the overall bearing when leaving the colony. This will be especially important for species such as fulmars that rely on dynamic soaring for long-ranging flight (Furness \& Bryant 1996). In general, decoupling movement steps from movement phases allows disentangling the processes influencing movement at multiple scales (Nathan et al. 2008). As a result, the model may potentially be adapted to any setting in which a species uses separate habitats for different activities or lifehistory stages. For example, it could be reformulated for the movements of migratory species, where the patterns of attraction switch seasonally, to assess the effects of anthropogenic activities at different stages of migration (e.g. Schofield et al. 2010). Finally, external agents need not be anthropogenic, and the approach could thus be used to model the influence of predators' distance on prey movements (e.g. Breed et al. 2017), the location of conspecifics in groups of social 
species (Boinski \& Garber 2000), or the availability of carcasses on the ranging pattern of scavengers (Kane et al. 2017). In essence, the model requires the estimation of bearings representing competing attraction or repulsion processes affecting an individual over time, and extensive telemetry datasets are already available to develop many of these possible extensions. These applications will improve our understanding of the functional mechanisms driving animal behaviour and how both natural and anthropogenic drivers influence movement patterns.

\section{Acknowledgements}

We thank Orkney Islands Council for access to Eynhallow and Talisman Energy (UK) Ltd for fieldwork and equipment support. Marine Scotland provided access to anonymized VMS data. Handling and tagging of fulmars was conducted under licenses from the British Trust for Ornithology and the UK Home Office. EE was funded by a Marine Alliance for Science and Technology for Scotland/University of Aberdeen College of Life Sciences and Medicine studentship. We are grateful to Jason Matthiopoulos, Thomas Cornulier, Beth Scott, David Lusseau, Julien Martin and Tiago Marques for suggestions on model development, and to the many colleagues who assisted with fieldwork. We thank Emer Rogan and University College Cork for providing desk space to EP. Finally, we thank Editor-in-Chief Ben Sheldon, Associate Editor Luca Borger and three anonymous reviewers for their useful comments on the paper.

Author contributions: All authors contributed to discussions that led to the development of the study. PT and EE designed and managed the data collection; EP, EE and PT conceived the research question; EP and LN developed the modelling approach; EP led the analysis and the 
writing of the manuscript. All authors contributed critically to the drafts and gave final approval for publication.

\section{Data accessibility}

Data available from the Dryad Digital Repository: https://doi:10.5061/dryad.0d377r6 (Pirotta et al., 2018).

\section{References}

Bartumeus, F., Giuggioli, L., Louzao, M., Bretagnolle, V., Oro, D. \& Levin, S.A. (2010) Fishery discards impact on seabird movement patterns at regional scales. Current Biology, 20, 215222.

Beyer, H.L., Morales, J.M., Murray, D. \& Fortin, M.J. (2013) The effectiveness of Bayesian state-space models for estimating behavioural states from movement paths. Methods in Ecology and Evolution, 4, 433-441.

Bicknell, A.W.J., Oro, D., Camphuysen, K.C.J. \& Votier, S.C. (2013) Potential consequences of discard reform for seabird communities. Journal of Applied Ecology, 50, 649-658.

Bodey, T.W., Jessopp, M.J., Votier, S.C., Gerritsen, H.D., Cleasby, I.R., Hamer, K.C., Patrick, S.C., Wakefield, E.D. \& Bearhop, S. (2014) Seabird movement reveals the ecological footprint of fishing vessels. Current biology, 24, 514-515.

Boinski, S. \& Garber, P. (2000) On the Move: How and Why Animals Travel in Groups. University of Chicago Press, Chicago. 
Boyd, C., Punt, A.E., Weimerskirch, H. \& Bertrand, S. (2014) Movement models provide insights into variation in the foraging effort of central place foragers. Ecological Modelling, 286, 13-25.

Breed, G.A., Matthews, C.J.D., Marcoux, M., Higdon, J.W., LeBlanc, B., Petersen, S.D., Orr, J., Reinhart, N.R. \& Ferguson, S.H. (2017) Sustained disruption of narwhal habitat use and behavior in the presence of Arctic killer whales. Proceedings of the National Academy of Sciences, 114, 2628-2633.

Calenge, C. (2006) The package adehabitat for the R software: a tool for the analysis of space and habitat use by animals. Ecological Modelling, 197, 516-519.

Cohen, L., Pichegru, L., Grémillet, D., Coetzee, J., Upfold, L. \& Ryan, P. (2014) Changes in prey availability impact the foraging behaviour and fitness of Cape gannets over a decade. Marine Ecology Progress Series, 505, 281-293.

Collet, J., Patrick, S.C. \& Weimerskirch, H. (2017a) A comparative analysis of the behavioral response to fishing boats in two albatross species. Behavioral Ecology, 28, 1337-1347.

Collet, J., Patrick, S.C. \& Weimerskirch, H. (2017b) Behavioral responses to encounter of fishing boats in wandering albatrosses. Ecology and Evolution, 7, 3335-3347.

Crowder, L. \& Norse, E. (2008) Essential ecological insights for marine ecosystem-based management and marine spatial planning. Marine Policy, 32, 772-778.

Dean, B., Freeman, R., Kirk, H., Leonard, K., Phillips, R.A., Perrins, C.M. \& Guilford, T. (2013) Behavioural mapping of a pelagic seabird: combining multiple sensors and a hidden Markov model reveals the distribution of at-sea behaviour. Journal of the Royal Society 
Interface, 10, 20120570.

Furness, R.W. \& Bryant, D.M. (1996) Effect of wind on field metabolic rates of breeding northern fulmars. Ecology, 77, 1181-1188.

Granadeiro, J.P., Brickle, P. \& Catry, P. (2014) Do individual seabirds specialize in fisheries' waste? The case of black-browed albatrosses foraging over the Patagonian Shelf. Animal Conservation, 17, 19-26.

Grémillet, D., Wright, G., Lauder, A., David, N. \& Wanless, S. (2003) Modelling the daily food requirements of wintering great cormorants: a bioenergetics tool for wildlife management. Journal of Applied Ecology, 40, 266-277.

Hays, G.C., Ferreira, L.C., Sequeira, A.M.M., Meekan, M.G., Duarte, C.M., Bailey, H., Bailleul, F., Bowen, W.D., Caley, M.J., Costa, D.P., Eguíluz, V.M., Fossette, S., Friedlaender, A.S., Gales, N., Gleiss, A.C., Gunn, J., Harcourt, R., Hazen, E.L., Heithaus, M.R., Heupel, M., Holland, K., Horning, M., Jonsen, I., Kooyman, G.L., Lowe, C.G., Madsen, P.T., Marsh, H., Phillips, R.A., Righton, D., Ropert-Coudert, Y., Sato, K., Shaffer, S.A., Simpfendorfer, C.A., Sims, D.W., Skomal, G., Takahashi, A., Trathan, P.N., Wikelski, M., Womble, J.N. \& Thums, M. (2016) Key questions in marine megafauna movement ecology. Trends in Ecology and Evolution, 31, 463-475.

Hutchison, L.V. \& Wenzel, B.M. (1980) Olfactory function in the Northern Fulmar (Fulmaris glacialis). Olfaction and Taste (ed H. van der Starre), pp. 237-240. IRL Press, London, UK.

Jonsen, I., Basson, M., Bestley, S., Bravington, M.V., Patterson, T.A., Pedersen, M.W., Thomson, R., Thygesen, U.H. \& Wotherspoon, S.J. (2013) State-space models for biologgers: A methodological road map. Deep Sea Research Part II: Topical Studies in 
Oceanography, 88-89, 34-46.

Kane, A., Healy, K., Guillerme, T., Ruxton, G.D. \& Jackson, A.L. (2017) A recipe for scavenging in vertebrates - the natural history of a behaviour. Ecography, 40, 324-334.

Kareiva, P. \& Odell, G. (1987) Swarms of predators exhibit "preytaxis" if individual predators use area-restricted search. The American Naturalist, 130, 233.

Karpouzi, V.S., Watson, R. \& Pauly, D. (2007) Modelling and mapping resource overlap between seabirds and fisheries on a global scale: A preliminary assessment. Marine Ecology Progress Series, 343, 87-99.

Kelleher, K. (2005) Discards in the World's Marine Fisheries: An Update. FAO Fisheries Technical Paper, No. 470. Food and Agriculture Organization of the United Nations, Rome, Italy.

Lewison, R.L., Crowder, L.B., Wallace, B.P., Moore, J.E., Cox, T., Zydelis, R., McDonald, S., Dimatteo, A., Dunn, D.C., Kot, C.Y., Bjorkland, R., Kelez, S., Soykan, C., Stewart, K.R., Sims, M., Boustany, A., Read, A.J., Halpin, P., Nichols, W.J. \& Safina, C. (2014) Global patterns of marine mammal, seabird, and sea turtle bycatch reveal taxa-specific and cumulative megafauna hotspots. Proceedings of the National Academy of Sciences of the United States of America, 111, 5271-5276.

Link, W.A. \& Eaton, M.J. (2012) On thinning of chains in MCMC. Methods in Ecology and Evolution, 3, 112-115.

Lunn, D., Jackson, C., Best, N., Thomas, A. \& Spiegelhalter, D. (2013) The BUGS Book: A Practical Introduction to Bayesian Analysis. Chapman \& Hall/CRC, Boca Raton, Florida, 


\section{USA.}

McClintock, B.T., King, R., Thomas, L., Matthiopoulos, J., McConnell, B.J. \& Morales, J.M. (2012) A general discrete-time modeling framework for animal movement using multistate random walks. Ecological Monographs, 82, 335-349.

McClintock, B.T., Russell, D.J.F., Matthiopoulos, J. \& King, R. (2013) Combining individual animal movement and ancillary biotelemetry data to investigate population-level activity budgets. Ecology, 94, 838-849.

Michelot, T., Langrock, R., Bestley, S., Jonsen, I.D., Photopoulou, T. \& Patterson, T.A. (2017) Estimation and simulation of foraging trips in land-based marine predators. Ecology, 98, 1932-1944.

Michelot, T., Langrock, R. \& Patterson, T.A. (2016) moveHMM: an R package for the statistical modelling of animal movement data using hidden Markov models. Methods in Ecology and Evolution, 7, 1308-1315.

Morales, J.M., Haydon, D.T., Frair, J., Holsinger, K.E. \& Fryxell, J.M. (2004) Extracting more out of relocation data: building movement models as mixtures of random walks. Ecology, 85, 2436-2445.

Nathan, R., Getz, W.M., Revilla, E., Holyoak, M., Kadmon, R., Saltz, D. \& Smouse, P.E. (2008) A movement ecology paradigm for unifying organismal movement research. Proceedings of the National Academy of Sciences, 105, 19052-19059.

Nevitt, G.A. (2008) Sensory ecology on the high seas: the odor world of the procellariiform seabirds. Journal of Experimental Biology, 211, 1706-1713. 
Orians, G.H. \& Pearson, N.E. (1979) On the theory of central place foraging. Analysis of ecological systems (eds D.J. Horn, R.D. Mitchell \& G.R. Stairs), pp. 155-177. Ohio State University Press, Columbus, $\mathrm{OH}$.

Patrick, S.C., Bearhop, S., Bodey, T.W., Grecian, W.J., Hamer, K.C., Lee, J. \& Votier, S.C. (2015) Individual seabirds show consistent foraging strategies in response to predictable fisheries discards. Journal of Avian Biology, 46, 1-10.

Patrick, S.C., Bearhop, S., Grémillet, D., Lescroël, A., Grecian, W.J., Bodey, T.W., Hamer, K.C., Wakefield, E., Le Nuz, M. \& Votier, S.C. (2014) Individual differences in searching behaviour and spatial foraging consistency in a central place marine predator. Oikos, 123, $33-40$.

Patterson, T.A., Thomas, L., Wilcox, C., Ovaskainen, O. \& Matthiopoulos, J. (2008) State-space models of individual animal movement. Trends in Ecology \& Evolution, 23, 87-94.

Phillips, R.A., Petersen, M.K., Lilliendahl, K., Solmundsson, J., Hamer, K.C., Camphuysen, C.J. \& Zonfrillo, B. (1999) Diet of the northern fulmar Fulmarus glacialis: Reliance on commercial fisheries? Marine Biology, 135, 159-170.

Pirotta, E., Edwards, E.W.J., New, L., Thompson, P.M. (2018) Data from: Central place foragers and moving stimuli: a hidden-state model to discriminate the processes affecting movement. Dryad Digital Repository, https://doi:10.5061/dryad.0d377r6

Plummer, M., Best, N., Cowles, K. \& Vines, K. (2006) CODA: Convergence Diagnosis and Output Analysis for MCMC. R News, 6, 7-11.

R Development Core Team. (2016) R: A language and environment for statistical computing. R 
Foundation for Statistical Computing, Vienna, Austria. ISBN 3-900051-07-0, URL http://www.R-project.org/.

Russell, D.J.F., Brasseur, S.M.J.M., Thompson, D., Hastie, G.D., Janik, V.M., Aarts, G., McClintock, B.T., Matthiopoulos, J., Moss, S.E.W. \& McConnell, B. (2014) Marine mammals trace anthropogenic structures at sea. Current Biology, 24, 638-639.

Russell, D.J.F., Hastie, G.D., Thompson, D., Janik, V.M., Hammond, P.S., Scott-Hayward, L.A.S., Matthiopoulos, J., Jones, E.L., McConnell, B.J. \& Votier, S. (2016) Avoidance of wind farms by harbour seals is limited to pile driving activities. Journal of Applied Ecology, 53, $1642-1652$.

Schofield, G., Hobson, V.J., Fossette, S., Lilley, M.K.S., Katselidis, K.A. \& Hays, G.C. (2010) Fidelity to foraging sites, consistency of migration routes and habitat modulation of home range by sea turtles. Diversity and Distributions, 16, 840-853.

Sepúlveda, M., Newsome, S.D., Pavez, G., Oliva, D., Costa, D.P. \& Hückstädt, L.A. (2015) Using satellite tracking and isotopic information to characterize the impact of South American sea lions on Salmonid aquaculture in Southern Chile. PLOS ONE, 10, 1-18.

Stephens, D.W., Brown, J.S. \& Ydenberg, R.C. (2007) Foraging: Behavior and Ecology. The University of Chicago Press, Chicago.

Sturtz, S., Ligges, U. \& Gelman, A. (2005) R2WinBUGS: A Package for Running WinBUGS from R. Journal of Statistical Software, 12, 1-16.

Tew Kai, E., Benhamou, S., van der Lingen, C.D., Coetzee, J.C., Pichegru, L., Ryan, P.G. \& Grémillet, D. (2013) Are Cape gannets dependent upon fishery waste? A multi-scale 
analysis using seabird GPS-tracking, hydro-acoustic surveys of pelagic fish and vessel monitoring systems. Journal of Applied Ecology, 50, 659-670.

Thompson, P.M. \& Ollason, J.C. (2001) Lagged effects of ocean climate change on fulmar population dynamics. Nature, 413, 417-420.

Torres, L.G., Thompson, D.R., Bearhop, S., Votier, S., Taylor, G.A., Sagar, P.M. \& Robertson, B.C. (2011) White-capped albatrosses alter fine-scale foraging behavior patterns when associated with fishing vessels. Marine Ecology Progress Series, 428, 289-301.

Votier, S.C., Bearhop, S., Witt, M.J., Inger, R., Thompson, D. \& Newton, J. (2010) Individual responses of seabirds to commercial fisheries revealed using GPS tracking, stable isotopes and vessel monitoring systems. Journal of Applied Ecology, 47, 487-497.

Votier, S.C., Furness, R.W., Bearhop, S., Crane, J.E., Caldow, R.W.G., Catry, P., Ensor, K., Hamer, K.C., Hudson, A. V., Kalmbach, E., Klomp, N.I., Pfeiffer, S., Phillips, R.A., Prieto, I. \& Thompson, D.R. (2004) Changes in fisheries discard rates and seabird communities. Nature, 427, 727-730.

Witt, M.J. \& Godley, B.J. (2007) A step towards seascape scale conservation: Using vessel monitoring systems (VMS) to map fishing activity. PLOS ONE, 2.

\section{Supporting Information}

The following Supporting Information is available for this article online:

Figure S1. Distribution of distances of fulmar locations from the closest boats.

Figure S2. Example of posterior results for the concentration of bearing under state 2. 
Figure S3. Interactions between fulmars and fishing boats.

Table S1. Description of variables and model parameters.

Table S2. Prior distributions of model parameters.

Table S3. Posterior estimates of model parameters.

Table S4. Estimated activity budget by each combination of the two states.

Table S5. Estimated activity budget of tracked fulmars during each foraging trip.

Appendix S1. OpenBUGS code for the model.

Appendix S2. Animations of fulmar movement and interactions with fishing boats.

Appendix S3. Implementation of the method by Torres et al. (2011) to account for the uncertainty in boat interpolated locations.

Figure S4. Schematic diagram of the circular spatial buffer around each interpolated location, calculated following the method by Torres et al. (2011).

Table S6. Posterior estimates of parameters for the model implementing the method by Torres et al. (2011).

Appendix S4. Reformulation of the model using a different set of distributions for the observed variables.

Table S7. Posterior estimates of parameters for the model reformulated with alternative distributions.

Appendix S5. Reformulation of the model with an additional state representing movement with unknown bearing. 
Table S8. Posterior estimates of parameters for the model with an additional state representing movement with unknown bearing.

Figure S5. Fulmar tracks classified using the model with an additional state representing movement with unknown bearing.

Table S9. Posterior estimates of parameters for a model without the trip-specific concentration of bearing parameters $\varepsilon$.

Appendix S6. Reformulation of the model with larger priors for the state-dependent distribution of distance from the closest boat. 


\section{Figures}

a

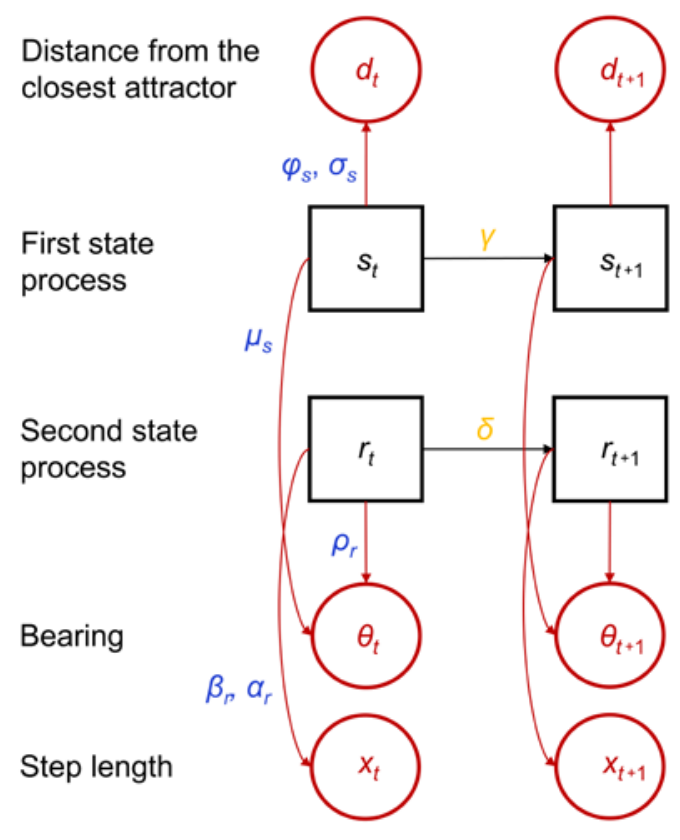

b

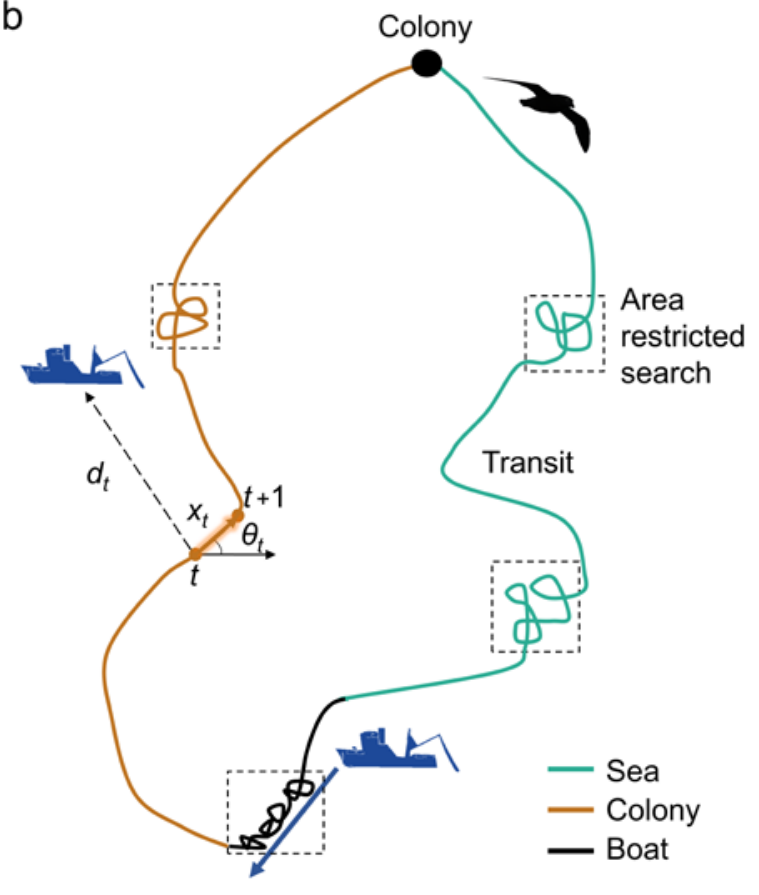

Figure 1. a) Schematic representation of the hidden Markov model. The black squares indicate the two hidden state processes, $\mathbf{s}$ and $\mathbf{r}$. The transition between states over time is indicated with black arrows, and the corresponding probabilities $(\gamma$ and $\delta$ ) are in yellow. State-dependent distributions (red arrows), characterised by state-dependent parameters (in blue; described in the text), determine the observations (step lengths $\mathbf{x}$, bearing $\boldsymbol{\theta}$ and distance from the closest attractor d; red circles) at each time step $t$. b) Schematic representation of a fulmar's foraging trip. The first state process regulates the movement phase: moving out to sea (green), towards a boat (black) or towards the colony (red). In this example, the bird followed one boat. The blue arrow indicates the direction of movement of the closest boat during this interaction. The second state process regulates the characteristics of the movement steps, distinguishing between resident (area restricted search; dashed boxes) and transit behaviour. State-dependent observations (step lengths $\mathbf{x}$, bearing $\boldsymbol{\theta}$ and distance from the closest boat $\mathbf{d}$ ) are exemplified for one time step $t$. 


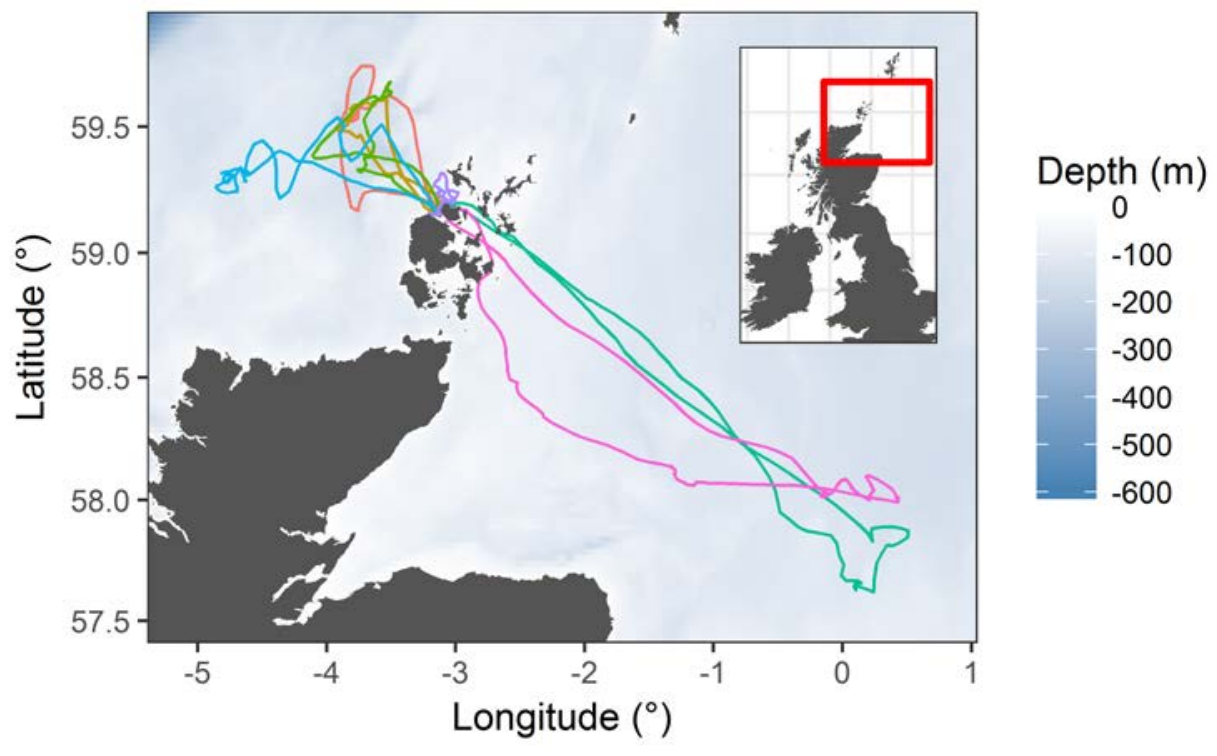

Figure 2. Map of the study area and fulmar GPS tracks, coloured by trip. 

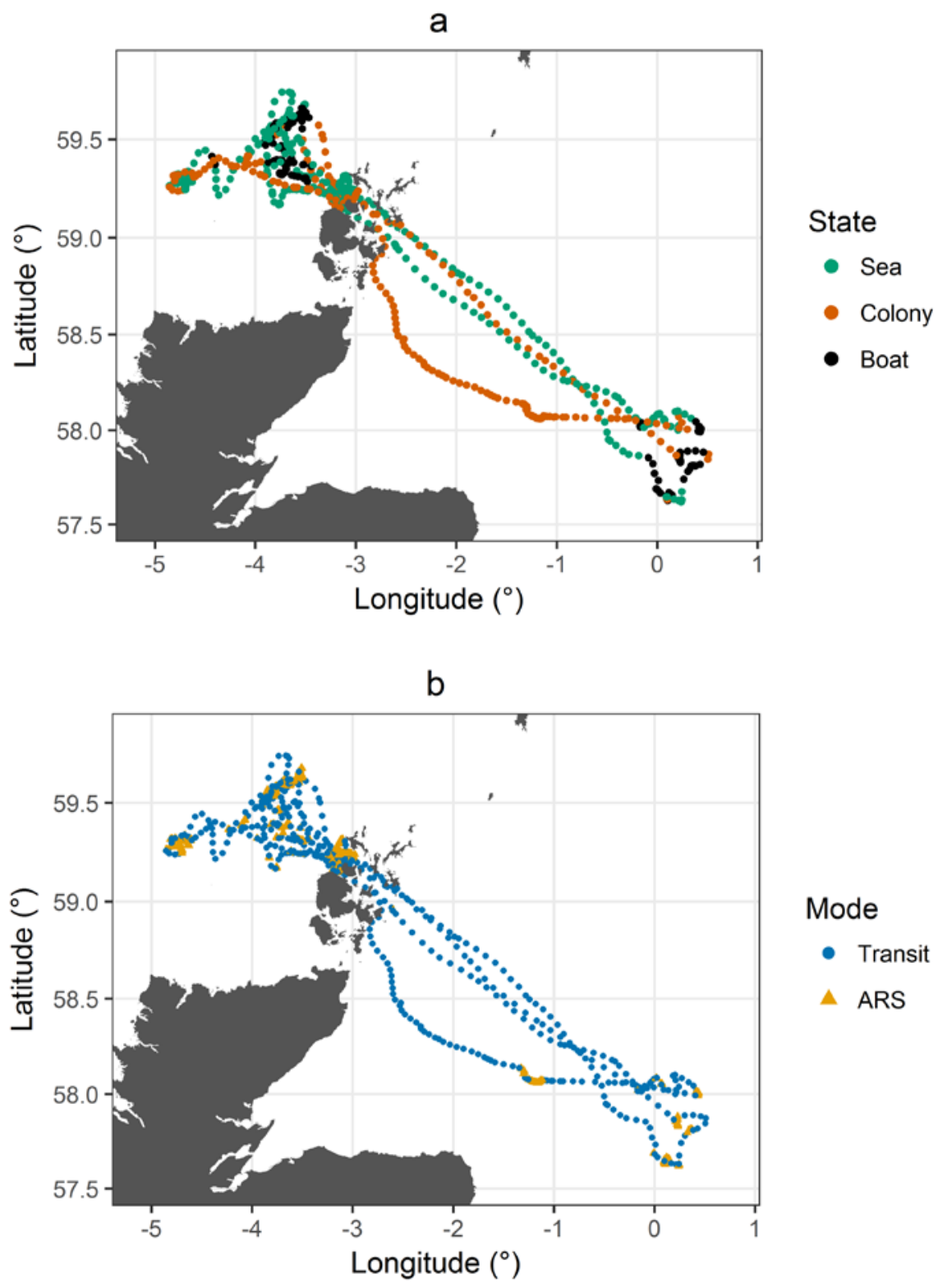

Figure 3. Fulmar tracks coloured by the latent behavioural states estimated by the model. In a), locations are classified based on the first state process, defining mean movement bearing. An individual can be in one of three states: heading out to sea (state 1), heading towards the colony (state 2) and heading towards the closest boat (state 3). In b), locations are classified based on the second state process, defining fine-scale movement mode. An individual can either be in transit (state 1) or in area restricted search (ARS) mode (state 2). 
a

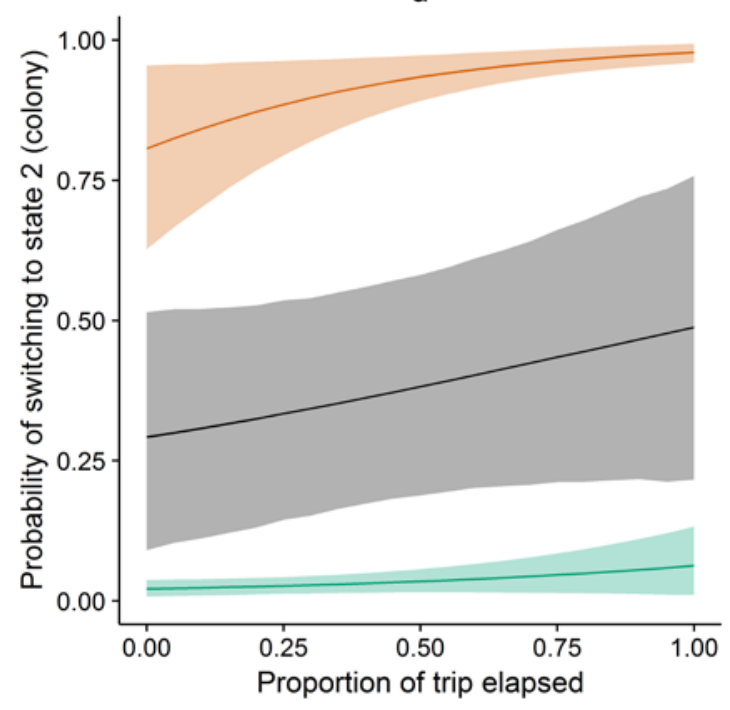

b

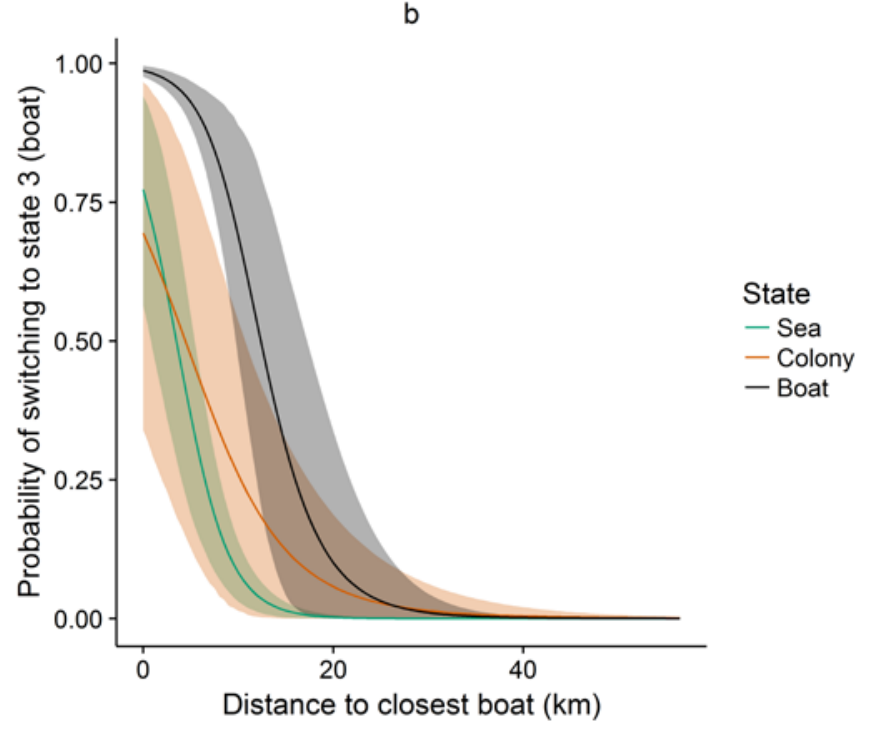

Figure 4. Estimated effects of covariates on state transition probabilities. In a), relationship between the elapsed proportion of a trip and the probability of switching from each state to state 2 (heading to the colony). In b), relationship between the distance to the closest boat and the probability of switching from each state to state 3 (heading towards the closest boat). 
a

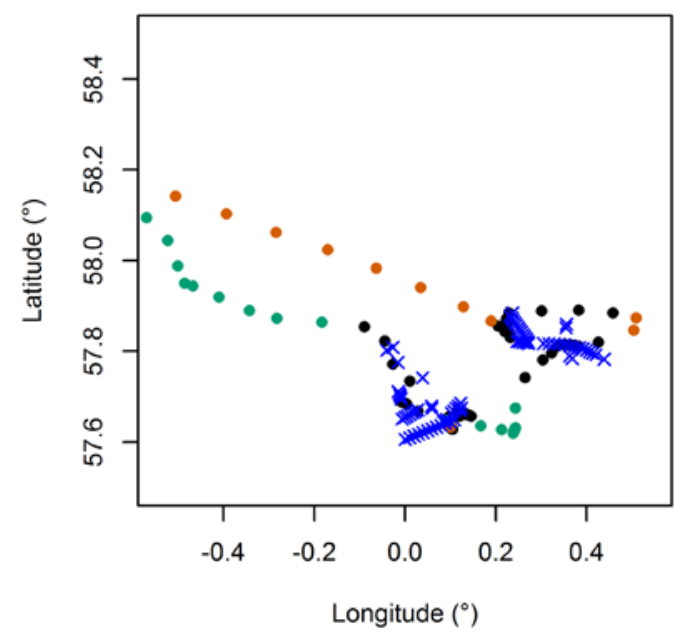

b

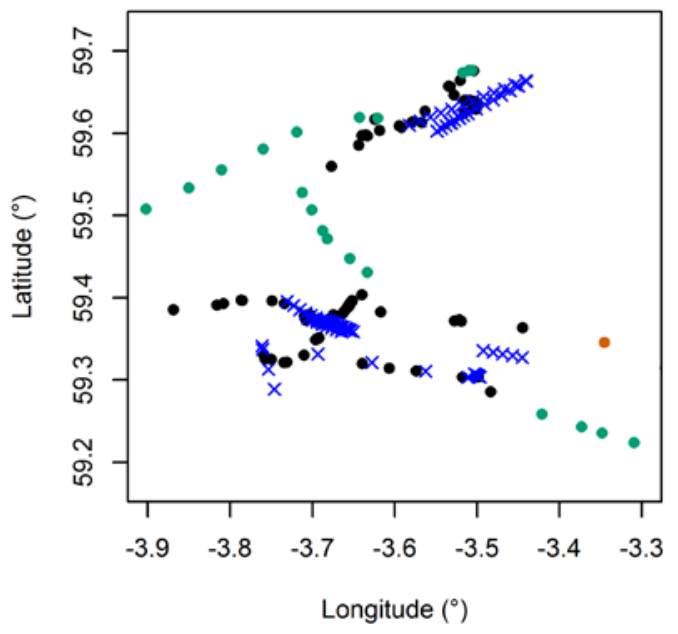

Bird state

- Sea

- Colony

- Boat

Boat

$\times$ Location

Figure 5. Examples of fulmar interactions with closest fishing boats estimated by the hidden state model. In a), a portion of the track from trip 4. In b), a portion of the track from trip 3. 


\section{Online Supporting information}

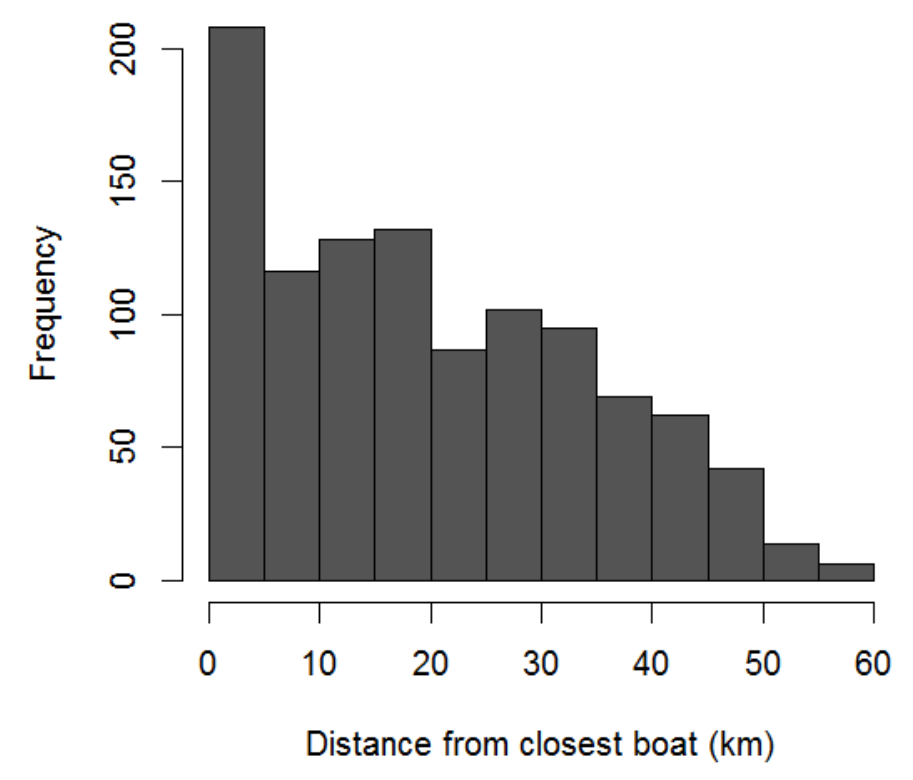

Figure S1. Distribution of distances between each interpolated location of a fulmar and the closest boat within a 5-minute time window.

a

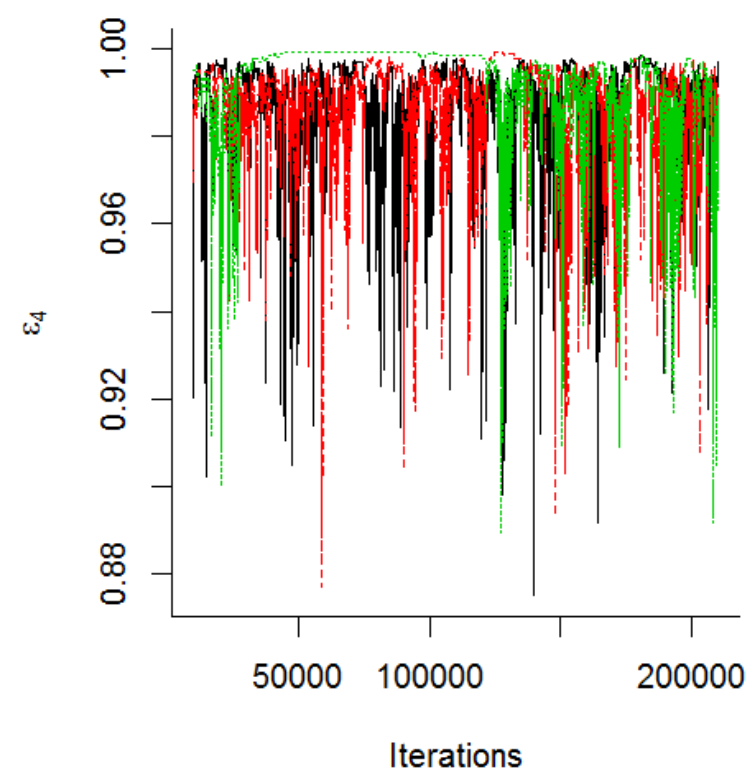

b

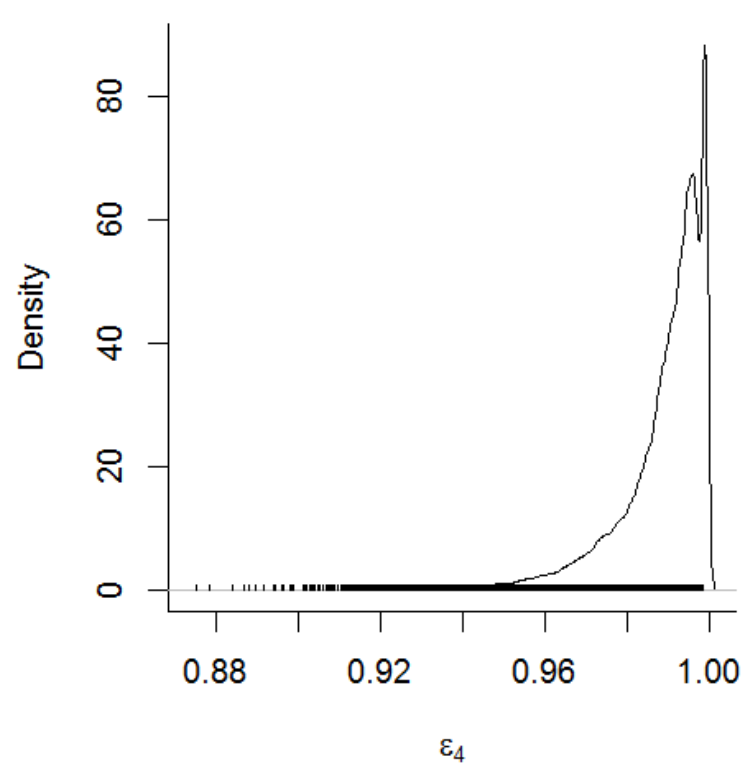

Figure S2. Example of posterior results for the concentration of flight bearing under state 2 (heading away from the colony) for trip $4, \varepsilon_{4}$. In a), the trace plot of the three parallel chains. In b), the posterior density distribution for the parameter. 


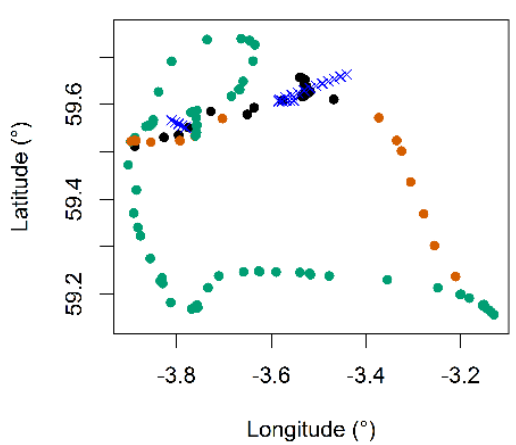

5

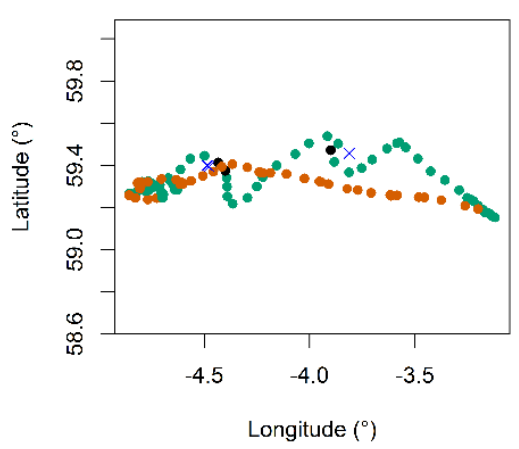

2
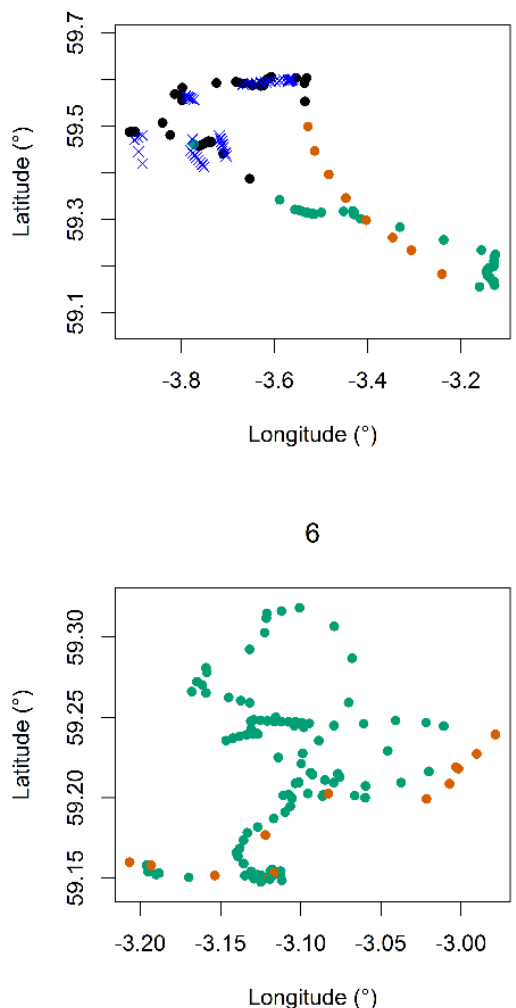

3

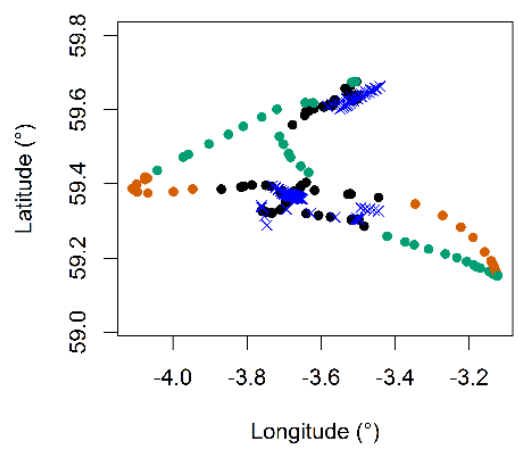

7

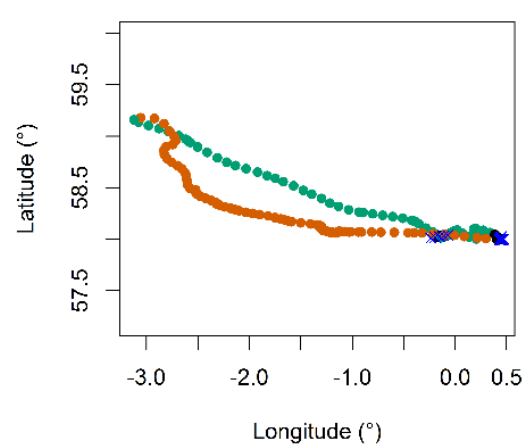

4

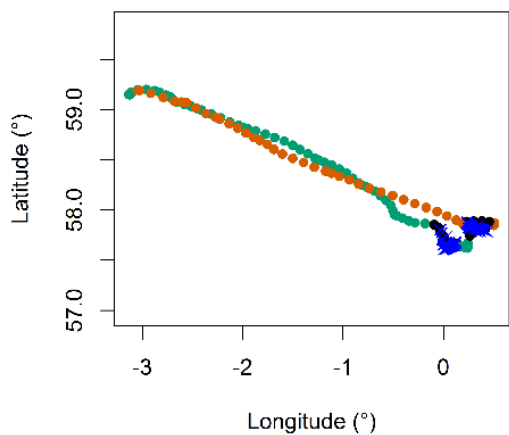

Bird state

- Sea

- Colony

- Boat

Boat

$\times$ Location

Figure S3. Interactions between fulmars and fishing boats, as defined by the first latent state process. Locations are classified based on the corresponding posterior state estimates. An individual can be in one of three states: heading out to sea (state 1, green), heading towards the colony (state 2, orange) and heading towards the closest boat (state 3, black). The closest boats are represented as blue crosses. Individual trips are plotted separately. 
Table S1. Description of variables and model parameters. The subscript $i$ and $t$ indicate the trip and the time step therein, respectively. Subscripts $s$ and $r$ indicate parameters that vary with either of the two state processes.

\begin{tabular}{|c|c|c|c|}
\hline Class & Symbol & Name & Definition \\
\hline \multirow{4}{*}{ Data } & $x_{i, t}$ & Step length & $\begin{array}{l}\text { Distance between consecutive } \\
\text { locations }\end{array}$ \\
\hline & $\theta_{i, t}$ & Observed bearing & $\begin{array}{l}\text { Absolute angle between the x- } \\
\text { axis (0) and a given step }\end{array}$ \\
\hline & $d_{i, t}$ & Attractor distance & $\begin{array}{c}\text { Distance from the closest } \\
\text { attractor }\end{array}$ \\
\hline & $v_{i}$ & Trip direction & $\begin{array}{c}\text { Angle between the central place } \\
\text { and the furthest location reached } \\
\text { during a trip }\end{array}$ \\
\hline \multirow{2}{*}{$\begin{array}{l}\text { Underlying } \\
\text { variables }\end{array}$} & $S_{i, t}$ & First state process & $\begin{array}{l}\text { Latent behavioural state } \\
\text { defining mean bearing } \\
\text { (movement phase) }\end{array}$ \\
\hline & $r_{i, t}$ & Second state process & $\begin{array}{l}\text { Latent behavioural state } \\
\text { defining fine-scale movement } \\
\text { features (movement step) }\end{array}$ \\
\hline \multirow{7}{*}{$\begin{array}{c}\text { Model } \\
\text { parameters }\end{array}$} & $\mu_{s, i, t}$ & Mean bearing & $\begin{array}{l}\text { Mean angle of a given step } \\
\text { measured from } 0 \text { radians }\end{array}$ \\
\hline & $\varepsilon_{i}$ & $\begin{array}{l}\text { Concentration of mean } \\
\text { bearing (state } 1 \text { ) }\end{array}$ & $\begin{array}{c}\text { Variability in mean bearing } \\
\text { under state } 1\end{array}$ \\
\hline & $\varphi_{s}$ & Mean distance & $\begin{array}{l}\text { Mean distance from the closest } \\
\text { attractor (log scale) }\end{array}$ \\
\hline & $\sigma_{s}$ & $\begin{array}{l}\text { Standard deviation of } \\
\text { distance }\end{array}$ & $\begin{array}{l}\text { Variability in distance from the } \\
\text { closest attractor (log scale) }\end{array}$ \\
\hline & $\rho_{r}$ & $\begin{array}{l}\text { Concentration of } \\
\text { observed bearing }\end{array}$ & Variability in observed bearing \\
\hline & $\alpha_{r}$ & Scale & $\begin{array}{l}\text { Scale parameter for the } \\
\text { distribution of step lengths }\end{array}$ \\
\hline & $\beta_{r}$ & Shape & $\begin{array}{l}\text { Shape parameter for the } \\
\text { distribution of step lengths }\end{array}$ \\
\hline
\end{tabular}




\begin{tabular}{|c|c|c|c|}
\hline$a_{h, 2}$ & $\begin{array}{c}\text { Logit transition } \\
\text { probability (state 2) }\end{array}$ & $\begin{array}{c}\text { Basal transition probability from } \\
\text { state } s_{i, t-1}=h \text { and } s_{i, t}=2 \text { on the } \\
\text { logit scale }\end{array}$ \\
\cline { 2 - 4 } & $a_{h, 3}$ & $\begin{array}{c}\text { Logit transition } \\
\text { probability (state 3) }\end{array}$ & $\begin{array}{c}\text { Basal transition probability from } \\
\text { state } s_{i, t-1}=h \text { and } s_{i, t}=3 \text { on the } \\
\text { logit scale }\end{array}$ \\
\cline { 2 - 4 } & $b_{h, 2}$ & $\begin{array}{c}\text { Coefficient for trip } \\
\text { proportion }\end{array}$ & $\begin{array}{c}\text { Effect of elapsed trip proportion } \\
\text { on transition probability from } \\
s_{i, t-1}=h \text { to } s_{i, t}=2 \text { (logit scale) } \\
\text { Effect of distance from the } \\
\text { closest attractor on transition } \\
\text { probability from } s_{i, t-1}=h \text { to } s_{i, t}= \\
\text { 3 (logit scale) }\end{array}$ \\
\hline$b_{h, 3}$ & $\begin{array}{c}\text { Coefficient for distance } \\
\gamma_{h, j}\end{array}$ & $\begin{array}{c}\text { Transition probability } \\
\text { (first state process) }\end{array}$ & $\begin{array}{c}\text { Probability of switching } \\
\text { between } s_{i, t-1}=h \text { and } s_{i, t}=j\end{array}$ \\
\cline { 2 - 4 } & $\delta_{k, l}$ & $\begin{array}{c}\text { Transition probability } \\
\text { (second state process) }\end{array}$ & $\begin{array}{c}\text { Probability of } \text { switching } \\
\text { between } r_{i, t-1}=k \text { and } r_{i, t}=l\end{array}$ \\
\hline
\end{tabular}


Table S2. Prior distributions of model parameters. The subscripts $i$ and $t$ refer to trips and time steps within trips, respectively. Priors for the scale and shape parameters of the distribution of step lengths were defined on the logarithmic scale to avoid meaningless negative values. Upper limits for these distributions were chosen based on preliminary exploration of the data. Wider, unrealistic values caused the Weibull distribution to crash. The prior for the observed distribution of distances from the closest boat was truncated at 0 , because distances can only be positive. Larger Normal and Uniform distributions were tested (Appendix S6), but did not change model results. The priors for angle concentrations were bound between 0 and 1 by nature of these parameters, but some constraints were imposed to specify the relative degree of directedness between states. Particularly, we constrain state $r_{i, t}=2$ to be more convoluted than $r_{i, t}=1$ by specifying $\rho_{1}>\rho_{2}$, and set $\rho_{1} \geq 0.5$ because we want $r_{i, t}=1$ to represent directed movement. The priors for the intercept and slope of the linear predictor of the transition probabilities for state $s$ had an uninformative Normal distribution, resulting in a relatively wide prior centred on 0.5 on the inverse logit scale. Parameters $b_{h, 3}$ were an exception: a narrower prior was chosen in this case because the large values that distance from the closest boat could take caused transition probabilities to be exactly 0 or 1 , thus crashing the Categorical distribution. An uninformative Dirichlet distribution was used for the transition probabilities for state $r$.

\begin{tabular}{|c|c|c|}
\hline Description & Parameter & $\begin{array}{c}\text { Prior } \\
\end{array}$ \\
\hline \multirow{3}{*}{$\begin{array}{l}\text { Mean distance from closest boat under state } \\
\qquad S_{i, t}\end{array}$} & $\varphi_{1}$ & Truncated Normal $(3,1)\left[\varphi_{3},\right]$ \\
\hline & $\varphi_{2}$ & $\varphi_{1}$ \\
\hline & $\varphi_{3}$ & Truncated Normal $(1,1)[0]$, \\
\hline \multirow{3}{*}{$\begin{array}{l}\text { Standard deviation of distance from closest } \\
\text { boat under state } s_{i, t}\end{array}$} & $\sigma_{1}$ & Uniform $(0,1)$ \\
\hline & $\sigma_{2}$ & $\sigma_{1}$ \\
\hline & $\sigma_{3}$ & Uniform $\left(0, \sigma_{1}\right)$ \\
\hline $\begin{array}{l}\text { Trip-specific concentration of mean bearing } \\
\qquad \text { for state } s_{i, t}=1\end{array}$ & $\varepsilon_{i}$ & Uniform $(0,1)$ \\
\hline \multirow{2}{*}{ Concentration of observed bearing } & $\rho_{1}$ & Uniform $(0.5,1)$ \\
\hline & $\rho_{2}$ & Uniform $\left(0, \rho_{1}\right)$ \\
\hline \multirow{2}{*}{ Scale of step length distribution } & $\log \left(\alpha_{1}\right)$ & Uniform $(-10,-2.5)$ \\
\hline & $\log \left(\alpha_{2}\right)$ & Uniform $\left(-10, \log \left(\alpha_{1}\right)\right)$ \\
\hline \multirow{3}{*}{ Shape of step length distribution } & $\log \left(\beta_{1}\right)$ & Uniform $(-1,1.5)$ \\
\hline & $\log \left(\beta_{2}\right)$ & Uniform $(-1,1.5)$ \\
\hline & $a_{h, 2}$ & $\operatorname{Normal}(0,1)$ \\
\hline
\end{tabular}




\begin{tabular}{|c|c|c|}
\hline $\begin{array}{c}\text { Basal transition probability from state } s_{i, t-1}= \\
h \text { (logit scale) }\end{array}$ & $a_{h, 3}$ & Normal $(0,1)$ \\
\hline $\begin{array}{c}\text { Effect of elapsed trip proportion on } \\
\text { transition probability from state } s_{i, t-1}=h \text { to } \\
\text { state } s_{i, t}=2 \text { (logit scale) }\end{array}$ & $b_{h, 2}$ & Normal $(0.5,1)$ \\
\hline $\begin{array}{c}\text { Effect of distance to the closest boat on } \\
\text { transition probability from state } s_{i, t-1}=h \text { to } \\
\text { state } s_{i, t}=3 \text { (logit scale) }\end{array}$ & $b_{h, 3}$ & Normal $(-0.2,0.1)$ \\
\hline $\begin{array}{c}\text { Transition probabilities from state } r_{i, t-1}=k \\
\text { Trion }\end{array}$ & $\delta_{k, 1, \delta_{k, 2}}$ & Dirichlet $(1,1)$ \\
\hline
\end{tabular}


Table S3. Posterior estimates of model parameters (median and 95\% highest posterior density interval).

\begin{tabular}{|c|c|c|c|c|}
\hline Description & Parameter & $\begin{array}{l}\text { Lower } \\
(2.5 \%)\end{array}$ & Median & $\begin{array}{l}\text { Upper } \\
(97.5 \%)\end{array}$ \\
\hline \multirow{3}{*}{$\begin{array}{l}\text { Mean distance from closest } \\
\text { boat under state } s_{i, t}\end{array}$} & $\varphi_{1}$ & 3.05 & 3.10 & 3.15 \\
\hline & $\varphi_{2}$ & 3.05 & 3.10 & 3.15 \\
\hline & $\varphi_{3}$ & 0.80 & 0.90 & 0.99 \\
\hline \multirow{3}{*}{$\begin{array}{l}\text { Standard deviation of distance } \\
\text { from closest boat under state } \\
\qquad s_{i, t}\end{array}$} & $\sigma_{1}$ & 0.60 & 0.63 & 0.66 \\
\hline & $\sigma_{2}$ & 0.60 & 0.63 & 0.66 \\
\hline & $\sigma_{3}$ & 0.60 & 0.63 & 0.66 \\
\hline \multirow{7}{*}{$\begin{array}{l}\text { Trip-specific concentration of } \\
\text { mean bearing for state } s_{i, t}=1\end{array}$} & $\varepsilon_{1}$ & 0.36 & 0.56 & 0.74 \\
\hline & $\varepsilon_{2}$ & 0.81 & 0.96 & 1.00 \\
\hline & $\varepsilon_{3}$ & 0.61 & 0.83 & 0.98 \\
\hline & $\varepsilon_{4}$ & 0.96 & 0.99 & 1.00 \\
\hline & $\varepsilon_{5}$ & 0.51 & 0.67 & 0.81 \\
\hline & $\varepsilon_{6}$ & 0.06 & 0.33 & 0.69 \\
\hline & $\varepsilon_{7}$ & 0.95 & 0.99 & 1.00 \\
\hline \multirow{2}{*}{$\begin{array}{l}\text { Concentration of observed } \\
\text { bearing }\end{array}$} & $\rho_{1}$ & 0.79 & 0.81 & 0.84 \\
\hline & $\rho_{2}$ & 0.30 & 0.38 & 0.46 \\
\hline \multirow{2}{*}{$\begin{array}{l}\text { Scale of step length } \\
\text { distribution }\end{array}$} & $\alpha_{1}$ & 0.066 & 0.070 & 0.073 \\
\hline & $\alpha_{2}$ & 0.005 & 0.006 & 0.007 \\
\hline \multirow{2}{*}{$\begin{array}{l}\text { Shape of step length } \\
\quad \text { distribution }\end{array}$} & $\beta_{1}$ & 2.06 & 2.28 & 2.52 \\
\hline & $\beta_{2}$ & 0.90 & 0.97 & 1.05 \\
\hline \multirow{5}{*}{$\begin{array}{l}\text { Basal transition probability for } \\
\text { state } s_{i, t} \text { (logit scale) }\end{array}$} & $a_{1,2}$ & -4.69 & -3.88 & -3.16 \\
\hline & $a_{2,2}$ & 0.38 & 1.52 & 2.73 \\
\hline & $a_{3,2}$ & -2.11 & -0.95 & 0.17 \\
\hline & $a_{1,3}$ & 0.12 & 1.32 & 2.50 \\
\hline & $a_{2,3}$ & -0.95 & 0.99 & 2.73 \\
\hline
\end{tabular}




\begin{tabular}{|c|c|c|c|c|}
\hline & $a_{3,3}$ & 3.61 & 4.42 & 5.29 \\
\hline \multirow{3}{*}{$\begin{array}{c}\text { Effect of elapsed trip } \\
\text { proportion on transition } \\
\text { probability from state si,t-1 to } \\
\text { state } s_{i, t}=2 \text { (logit scale) }\end{array}$} & $b_{1,2}$ & -0.46 & 1.05 & 2.52 \\
\hline & $b_{2,2}$ & 0.85 & 2.35 & 3.86 \\
\hline & $b_{3,2}$ & -0.67 & 0.90 & 2.43 \\
\hline \multirow{3}{*}{$\begin{array}{l}\text { Effect of distance to the closest } \\
\text { boat on transition probability } \\
\text { from state } s_{i, t-1} \text { to state } s_{i, t}=3 \\
\text { (logit scale) }\end{array}$} & $b_{1,3}$ & -0.50 & -0.38 & -0.26 \\
\hline & $b_{2,3}$ & -0.37 & -0.22 & -0.09 \\
\hline & $b_{3,3}$ & -0.50 & -0.36 & -0.21 \\
\hline \multirow{4}{*}{$\begin{array}{c}\text { Transition probabilities for } \\
\text { state } r_{i, t}\end{array}$} & $\delta_{1,1}$ & 0.84 & 0.87 & 0.90 \\
\hline & $\delta_{1,2}$ & 0.10 & 0.13 & 0.16 \\
\hline & $\delta_{2,1}$ & 0.07 & 0.09 & 0.12 \\
\hline & $\delta_{2,2}$ & 0.88 & 0.91 & 0.93 \\
\hline \multirow{3}{*}{ State $s_{i, t}$ proportions } & $\lambda_{1,1}$ & 0.44 & 0.47 & 0.49 \\
\hline & $\lambda_{1,2}$ & 0.26 & 0.29 & 0.31 \\
\hline & $\lambda_{1,3}$ & 0.23 & 0.24 & 0.26 \\
\hline \multirow{2}{*}{ State $r_{i, t}$ proportions } & $\lambda_{2,1}$ & 0.41 & 0.43 & 0.45 \\
\hline & $\lambda_{2,2}$ & 0.54 & 0.57 & 0.59 \\
\hline
\end{tabular}


Table S4. Estimated activity budget by each combination of the two states.

\begin{tabular}{|c|c|c|c|c|}
\hline \multirow{2}{*}{\multicolumn{2}{|c|}{ State }} & \multicolumn{2}{|c|}{$\begin{array}{c}\begin{array}{c}\text { Second state } \\
\text { process }\end{array} \\
\end{array}$} & \\
\hline & & 1 (transit) & 2 (resident) & \\
\hline \multirow{3}{*}{$\begin{array}{c}\text { First state } \\
\text { process }\end{array}$} & 1 (sea) & $20.3 \%$ & $27.7 \%$ & $48.0 \%$ \\
\hline & 2 (colony) & $16.3 \%$ & $11.5 \%$ & $27.8 \%$ \\
\hline & 3 (boat) & $6.0 \%$ & $18.2 \%$ & $24.2 \%$ \\
\hline & & $42.6 \%$ & $57.4 \%$ & \\
\hline
\end{tabular}

Table S5. Estimated activity budget of tracked fulmars during each foraging trip. This is expressed as the percentage of locations classified under each state of the first state process (movement out to sea, towards the colony or towards a boat).

\begin{tabular}{|c|c|c|c|c|c|c|}
\hline \multirow{2}{*}{ Trip ID } & \multirow{2}{*}{ Individual } & \multicolumn{3}{|c|}{ First state process (s) } & \multicolumn{2}{c|}{ Second state process (r) } \\
\cline { 3 - 7 } & & 1 (sea) & 2 (colony) & 3 (boat) & 1 (transit) & 2 (ARS) \\
\hline 1 & 1 & $66.7 \%$ & $16.3 \%$ & $17.0 \%$ & $40.3 \%$ & $59.7 \%$ \\
\hline 2 & 1 & $46.3 \%$ & $7.4 \%$ & $46.3 \%$ & $26.9 \%$ & $73.1 \%$ \\
\hline 3 & 2 & $21.3 \%$ & $22.6 \%$ & $56.1 \%$ & $35.5 \%$ & $64.5 \%$ \\
\hline 4 & 3 & $36.9 \%$ & $25.6 \%$ & $37.4 \%$ & $51.7 \%$ & $48.3 \%$ \\
\hline 5 & 4 & $62.5 \%$ & $35.5 \%$ & $2.0 \%$ & $45.4 \%$ & $54.6 \%$ \\
\hline 6 & 5 & $89.3 \%$ & $10.7 \%$ & - & $11.6 \%$ & $88.4 \%$ \\
\hline 7 & 6 & $31.7 \%$ & $59.1 \%$ & $9.1 \%$ & $67.2 \%$ & $32.8 \%$ \\
\hline
\end{tabular}


Appendix S1. Code for the hidden-state model in OpenBUGS format.

Appendix S2. Animations of fulmar movement and interaction with fishing boats.

Appendix S3. Implementation of the method by Torres et al. (2011) to account for the uncertainty in boat interpolated locations.

Vessel Monitoring System (VMS) locations of fishing boats are accurate, but they are collected approximately every two hours, while the exact position of boats in between fixes is unknown. In this study, we linearly interpolated VMS locations to match fulmar locations every 10 minutes, a procedure that introduces an unknown level of uncertainty over unobserved periods. In order to test whether this uncertainty could influence the results of our model, we followed the method described by Torres et al. (2011) to estimate a circular spatial buffer around each interpolated location, which represents the area where the boat could have been at that time. Briefly, two consecutive VMS locations define a segment of a boat's track. The radius of the spatial buffer at each interpolated location within this segment depends on the reported speed of the boat at the extremes of the segment and the time taken to move between these extremes. If, for example, a boat was moving fast at the reported VMS locations but only covered a small distance over that time interval, the uncertainty around its locations in the unobserved period is greater than for a boat that covered approximately the expected distance given the speed and time difference. The position of each interpolated location along the segment also affects the radius of the relative buffer, reaching the maximum at the midpoint of the segment where the uncertainty on the boat's location is greatest. More details and a step by step description of the buffer calculation can be found in Torres et al. (2011). We followed their procedure and obtained, for each interpolated location, a value of buffer radius. We then identified four additional points for each location: two along the corresponding segment and two along a line passing through the location and perpendicular to the segment, at a distance from the interpolated location equal to the estimated radius of the buffer (Fig. S4).

We calculated the minimum $\left(d_{\min , i, t}\right)$ and maximum $\left(d_{\max , i, t}\right)$ distance from the closest boat of a fulmar in trip $i$, at each time step $t$, as the minimum and maximum distances between the bird's position and the five points (the interpolated location and the four additional locations) identified for each boat location. Similarly, we calculated the bearings to the five locations and extracted the minimum $\left(\chi_{\min , i, t}\right)$ and maximum $\left(\chi_{\max , i, t}\right)$ of these values. We used these minima and maxima to represent the range of potential distances and bearings to the closest boat given the uncertainty in its exact location. Specifically, we modified the model so that the distance and bearing to the closest boat could take any value in these ranges, i.e. $d_{i, t} \sim U\left(d_{\min , i, t}, d_{\max , i, t}\right)$ and $\mu_{3, i, t} \sim U\left(\chi_{\min , i, t}\right.$, $\left.\chi_{\text {max }, i, t}\right)$. Also, we specified a separate, state-dependent lognormal distribution for the minimum 
and maximum distances to the closest boat, $d_{\min , i, t} \sim \log N\left(\varphi_{\min , s}, \sigma_{\min , s}\right)$ and $d_{\max , i, t} \sim \log N\left(\varphi_{\max , s}\right.$, $\left.\sigma_{\max , s}\right)$.

The estimates of the parameters and associated uncertainty from this modified version of the model are reported in Table S4. With the exception of the parameters associated with the new lognormal distributions of minimum and maximum distance from the closest boat, the 95\% highest posterior density intervals for all parameters were largely overlapping between the two model formulations. We compared the state classification under the model incorporating boat uncertainty with the classification under the original model, and found that the new model formulation led to the same state classification in $97.4 \%$ and $99.3 \%$ of locations, for the first and second state process (s and $\mathbf{r}$ ) respectively.

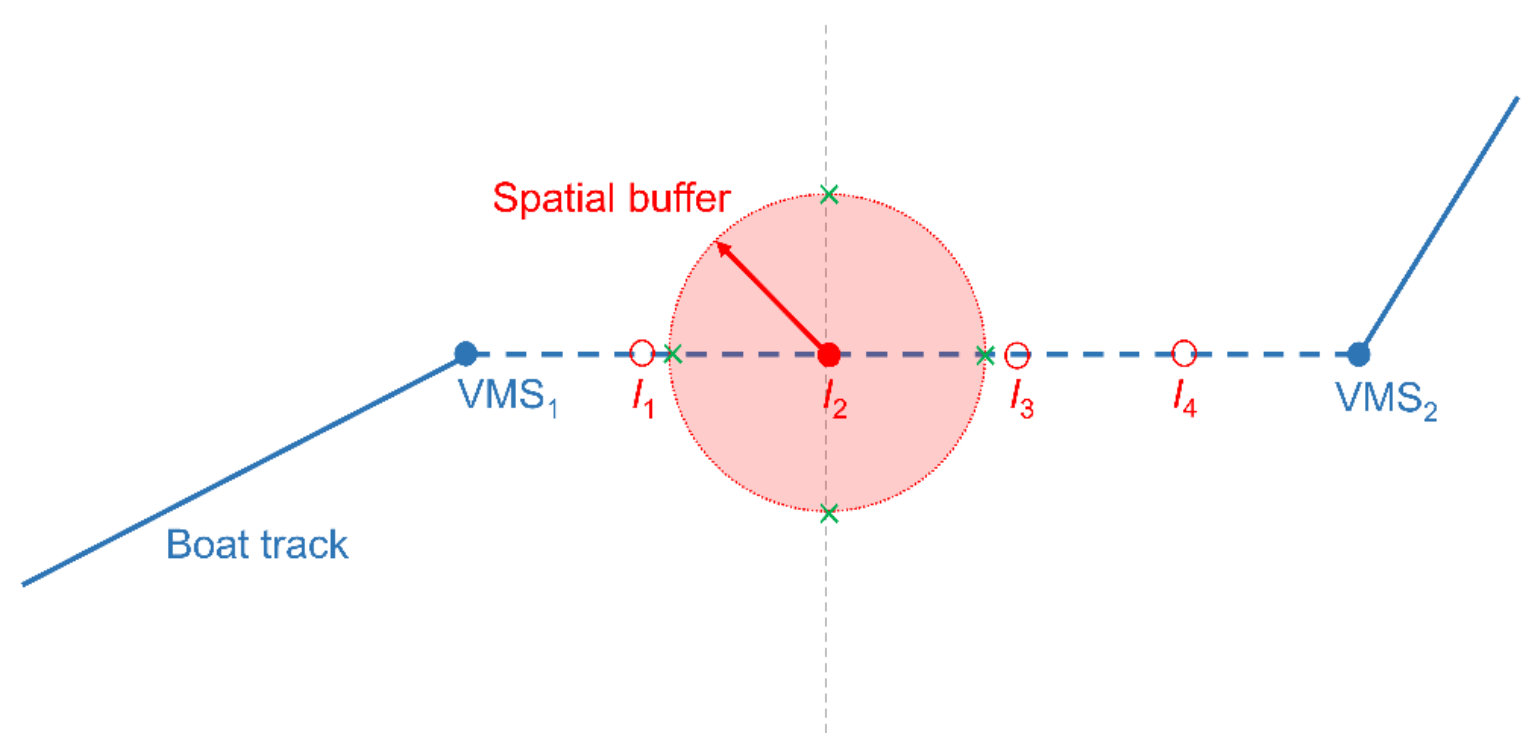

Figure S4. Schematic diagram of the circular spatial buffer around each interpolated location, calculated following the method by Torres et al. (2011). In blue, the track of a boat; the dashed portion represents a segment between two consecutive VMS fixes (indicated here as $\mathrm{VMS}_{1}$ and $\mathrm{VMS}_{2}$ ). The red dots, $I_{1-4}$, represent the interpolated locations within the segment. The red circle indicates the circular spatial buffer for location $I_{2}$, with the radius represented as a red arrow. The four additional locations used for the calculation of the range of a fulmar's distance and bearing to the boat are represented as green crosses. 
Table S6. Posterior estimates of parameters (median and 95\% highest posterior density interval) for the model implementing the method by Torres et al. (2011) to capture the uncertainty in boat locations.

\begin{tabular}{|c|c|c|c|c|}
\hline Description & Parameter & $\begin{array}{l}\text { Lower } \\
(2.5 \%)\end{array}$ & Median & $\begin{array}{c}\text { Upper } \\
(97.5 \%)\end{array}$ \\
\hline \multirow{3}{*}{$\begin{array}{l}\text { Mean minimum distance from } \\
\text { closest boat under state } s_{i, t}\end{array}$} & $\varphi_{\min , 1}$ & 2.95 & 3.00 & 3.05 \\
\hline & $\varphi_{\min , 2}$ & 2.95 & 3.00 & 3.05 \\
\hline & $\varphi_{\min , 3}$ & 0.48 & 0.58 & 0.68 \\
\hline \multirow{3}{*}{$\begin{array}{l}\text { Mean maximum distance from } \\
\text { closest boat under state } s_{i, t}\end{array}$} & $\varphi_{\max , 1}$ & 3.23 & 3.28 & 3.32 \\
\hline & $\varphi_{\max , 2}$ & 3.23 & 3.28 & 3.32 \\
\hline & $\varphi_{\max , 3}$ & 1.36 & 1.44 & 1.53 \\
\hline \multirow{3}{*}{$\begin{array}{l}\text { Standard deviation of } \\
\text { minimum distance from closest } \\
\text { boat under state } s_{i, t}\end{array}$} & $\sigma_{\min , 1}$ & 0.67 & 0.70 & 0.73 \\
\hline & $\sigma_{\min , 2}$ & 0.67 & 0.70 & 0.73 \\
\hline & $\sigma_{\min , 3}$ & 0.66 & 0.69 & 0.73 \\
\hline \multirow{3}{*}{$\begin{array}{c}\text { Standard deviation of } \\
\text { maximum distance from } \\
\text { closest boat under state } s_{i, t}\end{array}$} & $\sigma_{\max , 1}$ & 0.61 & 0.64 & 0.67 \\
\hline & $\sigma_{\max 2}$ & 0.61 & 0.64 & 0.67 \\
\hline & $\sigma_{\max , 3}$ & 0.61 & 0.63 & 0.66 \\
\hline \multirow{7}{*}{$\begin{array}{l}\text { Trip-specific concentration of } \\
\text { mean bearing for state } s_{i, t}=1\end{array}$} & $\varepsilon_{1}$ & 0.36 & 0.55 & 0.72 \\
\hline & $\varepsilon_{2}$ & 0.75 & 0.93 & 0.99 \\
\hline & $\varepsilon_{3}$ & 0.57 & 0.81 & 0.96 \\
\hline & $\varepsilon_{4}$ & 0.96 & 0.99 & 1.00 \\
\hline & $\varepsilon_{5}$ & 0.53 & 0.68 & 0.82 \\
\hline & $\varepsilon_{6}$ & 0.07 & 0.30 & 0.58 \\
\hline & $\varepsilon_{7}$ & 0.95 & 0.99 & 1.00 \\
\hline \multirow{2}{*}{$\begin{array}{l}\text { Concentration of observed } \\
\text { bearing }\end{array}$} & $\rho_{1}$ & 0.78 & 0.81 & 0.84 \\
\hline & $\rho_{2}$ & 0.37 & 0.45 & 0.52 \\
\hline \multirow{2}{*}{$\begin{array}{l}\text { Scale of step length } \\
\text { distribution }\end{array}$} & $\alpha_{1}$ & 0.066 & 0.070 & 0.073 \\
\hline & $\alpha_{2}$ & 0.005 & 0.006 & 0.007 \\
\hline
\end{tabular}




\begin{tabular}{|c|c|c|c|c|}
\hline \multirow{2}{*}{$\begin{array}{l}\text { Shape of step length } \\
\text { distribution }\end{array}$} & $\beta_{1}$ & 2.05 & 2.27 & 2.50 \\
\hline & $\beta_{2}$ & 0.91 & 0.98 & 1.06 \\
\hline \multirow{6}{*}{$\begin{array}{l}\text { Basal transition probability for } \\
\text { state } s_{i, t} \text { (logit scale) }\end{array}$} & $a_{1,2}$ & -4.66 & -3.85 & -3.14 \\
\hline & $a_{2,2}$ & 0.28 & 1.40 & 2.58 \\
\hline & $a_{3,2}$ & -2.19 & -1.04 & 0.06 \\
\hline & $a_{1,3}$ & 0.61 & 1.76 & 2.90 \\
\hline & $a_{2,3}$ & -0.96 & 1.13 & 3.02 \\
\hline & $a_{3,3}$ & 3.87 & 4.70 & 5.62 \\
\hline \multirow{3}{*}{$\begin{array}{c}\text { Effect of elapsed trip } \\
\text { proportion on transition } \\
\text { probability from state } s_{i, t-1} \text { to } \\
\text { state } s_{i, t}=2(\text { logit scale })\end{array}$} & $b_{1,2}$ & -0.46 & 1.04 & 2.45 \\
\hline & $b_{2,2}$ & 0.93 & 2.39 & 3.88 \\
\hline & $b_{3,2}$ & -0.72 & 0.84 & 2.38 \\
\hline \multirow{3}{*}{$\begin{array}{c}\text { Effect of distance to the closest } \\
\text { boat on transition probability } \\
\text { from state } s_{i, t-1} \text { to state } s_{i, t}=3 \\
\text { (logit scale) }\end{array}$} & $b_{1,3}$ & -0.51 & -0.40 & -0.29 \\
\hline & $b_{2,3}$ & -0.37 & -0.22 & -0.09 \\
\hline & $b_{3,3}$ & -0.45 & -0.34 & -0.23 \\
\hline \multirow{4}{*}{$\begin{array}{c}\text { Transition probabilities for } \\
\text { state } r_{i, t}\end{array}$} & $\delta_{1,1}$ & 0.84 & 0.87 & 0.90 \\
\hline & $\delta_{1,2}$ & 0.10 & 0.13 & 0.16 \\
\hline & $\delta_{2,1}$ & 0.07 & 0.09 & 0.12 \\
\hline & $\delta_{2,2}$ & 0.88 & 0.91 & 0.93 \\
\hline \multirow{3}{*}{ State $s_{i, t}$ proportions } & $\lambda_{1,1}$ & 0.45 & 0.47 & 0.49 \\
\hline & $\lambda_{1,2}$ & 0.26 & 0.28 & 0.30 \\
\hline & $\lambda_{1,3}$ & 0.24 & 0.25 & 0.26 \\
\hline \multirow{2}{*}{ State $r_{i, t}$ proportions } & $\lambda_{2,1}$ & 0.41 & 0.43 & 0.46 \\
\hline & $\lambda_{2,2}$ & 0.54 & 0.57 & 0.59 \\
\hline
\end{tabular}


Appendix S4. Reformulation of the model using a different set of distributions for the observed variables.

In our model, the step length at time $t$ of trip $i, x_{i, t}$, was assumed to emerge from a Weibull distribution with state-specific scale $\left(\alpha_{r}\right)$ and shape $\left(\beta_{r}\right)$ parameters, i.e. $x_{i, t} \sim W\left(\beta_{r}, \alpha_{r}\right)$, while the observed bearing $\theta_{i, t}$ was assumed to have a wrapped Cauchy distribution with mean $\mu_{s, i, t}$ and concentration parameter $\rho_{r}$, i.e. $\theta_{i, t} \sim w C\left(\mu_{s, i, t}, \rho_{r}\right)$ (Morales et al. 2004; McClintock et al. 2012, 2013). To assess whether the choice of such distributions affected the results, we reformulated the model using an alternative set of distributions that are also commonly used to model step lengths and angles in animal movement models (Michelot, Langrock \& Patterson 2016; Michelot et al. 2017). Particularly, step lengths were modelled using a Gamma distribution with statespecific shape $\left(\zeta_{r}\right)$ and rate $\left(\eta_{r}\right)$ parameters, i.e. $x_{i, t} \sim \Gamma\left(\zeta_{r}, \eta_{r}\right) . \zeta_{r}$ had uniform prior $U(0,7)$ and $\zeta_{2}$ $<\zeta_{1} . \eta_{r}$ had a uniform prior $U(1,500)$. Bearings were modelled using a von Mises distribution with mean $\mu_{s, i, t}$ and concentration parameter $\kappa_{r}$, i.e. $\theta_{i, t} \sim v M\left(\mu_{s, i, t}, \kappa_{r}\right)$. The mean $\mu_{s, i, t}$ was computed as described in the main text, while $\kappa_{r}$ could take any integer value between 0 and 40 and $\kappa_{2}<\kappa_{1}$. The values of the modified Bessel function of order $0, I_{0}\left(\kappa_{r}\right)$, required in the von Mises probability density function, were calculated in R for each integer value of $\kappa_{r}$ in the allowed range.

The estimates of the parameters and associated uncertainty from this alternative version of the model are reported in Table S5. With the exception of the parameters associated with the new implemented distributions, which are necessarily different, the $95 \%$ highest posterior density intervals for all parameters were largely overlapping between the two model formulations. We also compared the state classification under the new model with the classification under the original model, and found that the new model formulation led to the same state classification in $96.3 \%$ and $95.7 \%$ of locations, for the first and second state process ( $\mathbf{s}$ and $\mathbf{r}$ ) respectively. 
Table S7. Posterior estimates of parameters (median and 95\% highest posterior density interval) for the model reformulated with alternative distributions for bearing and step length.

\begin{tabular}{|c|c|c|c|c|}
\hline Description & Parameter & $\begin{array}{l}\text { Lower } \\
(2.5 \%)\end{array}$ & Median & $\begin{array}{c}\text { Upper } \\
(97.5 \%)\end{array}$ \\
\hline \multirow{3}{*}{$\begin{array}{c}\text { Mean distance from closest } \\
\text { boat under state } s_{i, t}\end{array}$} & $\varphi_{1}$ & 3.02 & 3.07 & 3.12 \\
\hline & $\varphi_{2}$ & 3.02 & 3.07 & 3.12 \\
\hline & $\varphi_{3}$ & 0.73 & 0.83 & 0.93 \\
\hline \multirow{3}{*}{$\begin{array}{l}\text { Standard deviation of distance } \\
\text { from closest boat under state } \\
\qquad s_{i, t}\end{array}$} & $\sigma_{1}$ & 0.62 & 0.65 & 0.68 \\
\hline & $\sigma_{2}$ & 0.62 & 0.65 & 0.68 \\
\hline & $\sigma_{3}$ & 0.61 & 0.64 & 0.67 \\
\hline \multirow{7}{*}{$\begin{array}{l}\text { Trip-specific concentration of } \\
\text { mean bearing for state } s_{i, t}=1\end{array}$} & $\varepsilon_{1}$ & 0.37 & 0.57 & 0.74 \\
\hline & $\varepsilon_{2}$ & 0.81 & 0.96 & 0.99 \\
\hline & $\varepsilon_{3}$ & 0.60 & 0.81 & 0.96 \\
\hline & $\varepsilon_{4}$ & 0.90 & 0.97 & 0.99 \\
\hline & $\varepsilon_{5}$ & 0.51 & 0.66 & 0.79 \\
\hline & $\varepsilon_{6}$ & 0.24 & 0.60 & 0.92 \\
\hline & $\varepsilon_{7}$ & 0.88 & 0.95 & 0.99 \\
\hline \multirow{2}{*}{$\begin{array}{l}\text { Concentration of observed } \\
\text { bearing }\end{array}$} & $\kappa_{1}$ & 9 & 11 & 13 \\
\hline & $\kappa_{2}$ & 2 & 2 & 2 \\
\hline \multirow{2}{*}{ Rate of step length distribution } & $\eta_{1}$ & 64.5 & 76.7 & 90.7 \\
\hline & $\eta_{2}$ & 89.4 & 110.1 & 139.3 \\
\hline \multirow{2}{*}{$\begin{array}{c}\text { Shape of step length } \\
\text { distribution }\end{array}$} & $\zeta_{1}$ & 4.21 & 5.05 & 6.04 \\
\hline & $\zeta_{2}$ & 0.79 & 0.88 & 0.99 \\
\hline \multirow{6}{*}{$\begin{array}{l}\text { Basal transition probability for } \\
\text { state } s_{i, t} \text { (logit scale) }\end{array}$} & $a_{1,2}$ & -4.61 & -3.84 & -3.14 \\
\hline & $a_{2,2}$ & 0.34 & 1.40 & 2.52 \\
\hline & $a_{3,2}$ & -2.04 & -0.89 & 0.22 \\
\hline & $a_{1,3}$ & -0.06 & 1.08 & 2.21 \\
\hline & $a_{2,3}$ & -0.56 & 1.18 & 2.79 \\
\hline & $a_{3,3}$ & 3.36 & 4.13 & 4.98 \\
\hline
\end{tabular}




\begin{tabular}{|c|c|c|c|c|}
\hline \multirow{3}{*}{$\begin{array}{c}\text { Effect of elapsed trip } \\
\text { proportion on transition } \\
\text { probability from state } s_{i, t-1} \text { to } \\
\text { state } s_{i, t}=2 \text { (logit scale) }\end{array}$} & $b_{1,2}$ & 0.08 & 1.49 & 2.87 \\
\hline & $b_{2,2}$ & 0.82 & 2.26 & 3.71 \\
\hline & $b_{3,2}$ & -0.52 & 1.06 & 2.62 \\
\hline \multirow{3}{*}{$\begin{array}{l}\text { Effect of distance to the closest } \\
\text { boat on transition probability } \\
\text { from state } s_{i, t-1} \text { to state } s_{i, t}=3 \\
\text { (logit scale) }\end{array}$} & $b_{1,3}$ & -0.50 & -0.37 & -0.26 \\
\hline & $b_{2,3}$ & -0.37 & -0.23 & -0.10 \\
\hline & $b_{3,3}$ & -0.49 & -0.34 & -0.18 \\
\hline \multirow{4}{*}{$\begin{array}{c}\text { Transition probabilities for } \\
\text { state } r_{i, t}\end{array}$} & $\delta_{1,1}$ & 0.82 & 0.86 & 0.90 \\
\hline & $\delta_{1,2}$ & 0.10 & 0.14 & 0.18 \\
\hline & $\delta_{2,1}$ & 0.06 & 0.08 & 0.11 \\
\hline & $\delta_{2,2}$ & 0.89 & 0.92 & 0.94 \\
\hline \multirow{3}{*}{ State $s_{i, t}$ proportions } & $\lambda_{1,1}$ & 0.45 & 0.47 & 0.49 \\
\hline & $\lambda_{1,2}$ & 0.28 & 0.30 & 0.33 \\
\hline & $\lambda_{1,3}$ & 0.21 & 0.22 & 0.24 \\
\hline \multirow{2}{*}{ State $r_{i, t}$ proportions } & $\lambda_{2,1}$ & 0.36 & 0.38 & 0.40 \\
\hline & $\lambda_{2,2}$ & 0.60 & 0.62 & 0.64 \\
\hline
\end{tabular}


Appendix S5. Reformulation of the model with an additional state representing movement with unknown bearing.

In alternative to allowing a variable mean bearing under state $s_{i, t}=1, \mu_{1, i, t}$, to capture the different directedness among trips, the model could be reformulated to include an extra state, $s_{i, t}=4$, representing movement off the main course of the trip. This state corresponded to any period where an individual was targeting localised areas (e.g. foraging patches) that were not aligned with the rest of the trip, thus further discriminating state 1 into two different phases: heading away from the central place towards the offshore region, and heading towards specific patches with unknown bearing. The fourth state was characterised by a random mean bearing, i.e. $\mu_{4, i, t} \sim$ Uniform $(-\pi, \pi)$ and the same distribution of distances to the closest attractor, $d_{i, t}$, as in state 1 and 2, i.e. $\varphi_{4}=\varphi_{1}=\varphi_{2}$ and $\sigma_{4}=\sigma_{1}=\sigma_{2}$. In contrast, the bearing for state 1 was fixed, i.e. $\mu_{1, i, t}=v_{i}$. The alternative model required the estimation of six additional basal transition probabilities on the logit scale, $a$, and two additional slope parameters, $b$ (Table S8).

The estimates of the parameters and associated uncertainty from this alternative version of the model are reported in Table S8. The comparison of the proportions of states $\mathbf{s}$ under the original and alternative versions of the model shows that most of the locations classified as $s_{i, t}=4(12 \%$ of the total, on average) were originally classified as $s_{i, t}=1$. The posterior proportion for this state declined from 0.47 to 0.35 . The plots of the foraging trips coloured by posterior state classification confirm the interpretation of the fourth state (Fig. S5). 
Table S8. Posterior estimates of parameters (median and 95\% highest posterior density interval) for the model with an additional state representing movement with unknown bearing.

\begin{tabular}{|c|c|c|c|c|}
\hline Description & Parameter & $\begin{array}{l}\text { Lower } \\
(2.5 \%)\end{array}$ & Median & $\begin{array}{c}\text { Upper } \\
(97.5 \%)\end{array}$ \\
\hline \multirow{4}{*}{$\begin{array}{c}\text { Mean distance from closest } \\
\text { boat under state } s_{i, t}\end{array}$} & $\varphi_{1}$ & 3.06 & 3.11 & 3.16 \\
\hline & $\varphi_{2}$ & 3.06 & 3.11 & 3.16 \\
\hline & $\varphi_{3}$ & 0.82 & 0.92 & 1.01 \\
\hline & $\varphi_{4}$ & 3.06 & 3.11 & 3.16 \\
\hline \multirow{4}{*}{$\begin{array}{l}\text { Standard deviation of distance } \\
\text { from closest boat under state } \\
\qquad s_{i, t}\end{array}$} & $\sigma_{1}$ & 0.60 & 0.63 & 0.66 \\
\hline & $\sigma_{2}$ & 0.60 & 0.63 & 0.66 \\
\hline & $\sigma_{3}$ & 0.60 & 0.63 & 0.65 \\
\hline & $\sigma_{4}$ & 0.60 & 0.63 & 0.66 \\
\hline \multirow{2}{*}{$\begin{array}{c}\text { Concentration of observed } \\
\text { bearing }\end{array}$} & $\rho_{1}$ & 0.77 & 0.80 & 0.83 \\
\hline & $\rho_{2}$ & 0.26 & 0.33 & 0.41 \\
\hline \multirow{2}{*}{$\begin{array}{c}\text { Scale of step length } \\
\text { distribution }\end{array}$} & $\alpha_{1}$ & 0.066 & 0.070 & 0.073 \\
\hline & $\alpha_{2}$ & 0.005 & 0.006 & 0.007 \\
\hline \multirow{2}{*}{$\begin{array}{c}\text { Shape of step length } \\
\text { distribution }\end{array}$} & $\beta_{1}$ & 2.05 & 2.27 & 2.50 \\
\hline & $\beta_{2}$ & 0.90 & 0.97 & 1.05 \\
\hline \multirow{10}{*}{$\begin{array}{l}\text { Basal transition probability for } \\
\text { state } s_{i, t} \text { (logit scale) }\end{array}$} & $a_{1,1}$ & 2.28 & 2.90 & 3.62 \\
\hline & $a_{2,1}$ & -2.22 & -0.59 & 0.81 \\
\hline & $a_{3,1}$ & -2.71 & -1.21 & 0.10 \\
\hline & $a_{4,1}$ & -2.97 & -1.85 & -0.50 \\
\hline & $a_{1,2}$ & -2.95 & -1.62 & -0.49 \\
\hline & $a_{2,2}$ & 0.66 & 1.88 & 3.19 \\
\hline & $a_{3,2}$ & -2.14 & -0.90 & 0.27 \\
\hline & $a_{4,2}$ & -3.65 & -2.45 & -1.20 \\
\hline & $a_{1,3}$ & 0.88 & 2.49 & 3.95 \\
\hline & $a_{2,3}$ & -1.51 & 0.60 & 2.61 \\
\hline
\end{tabular}




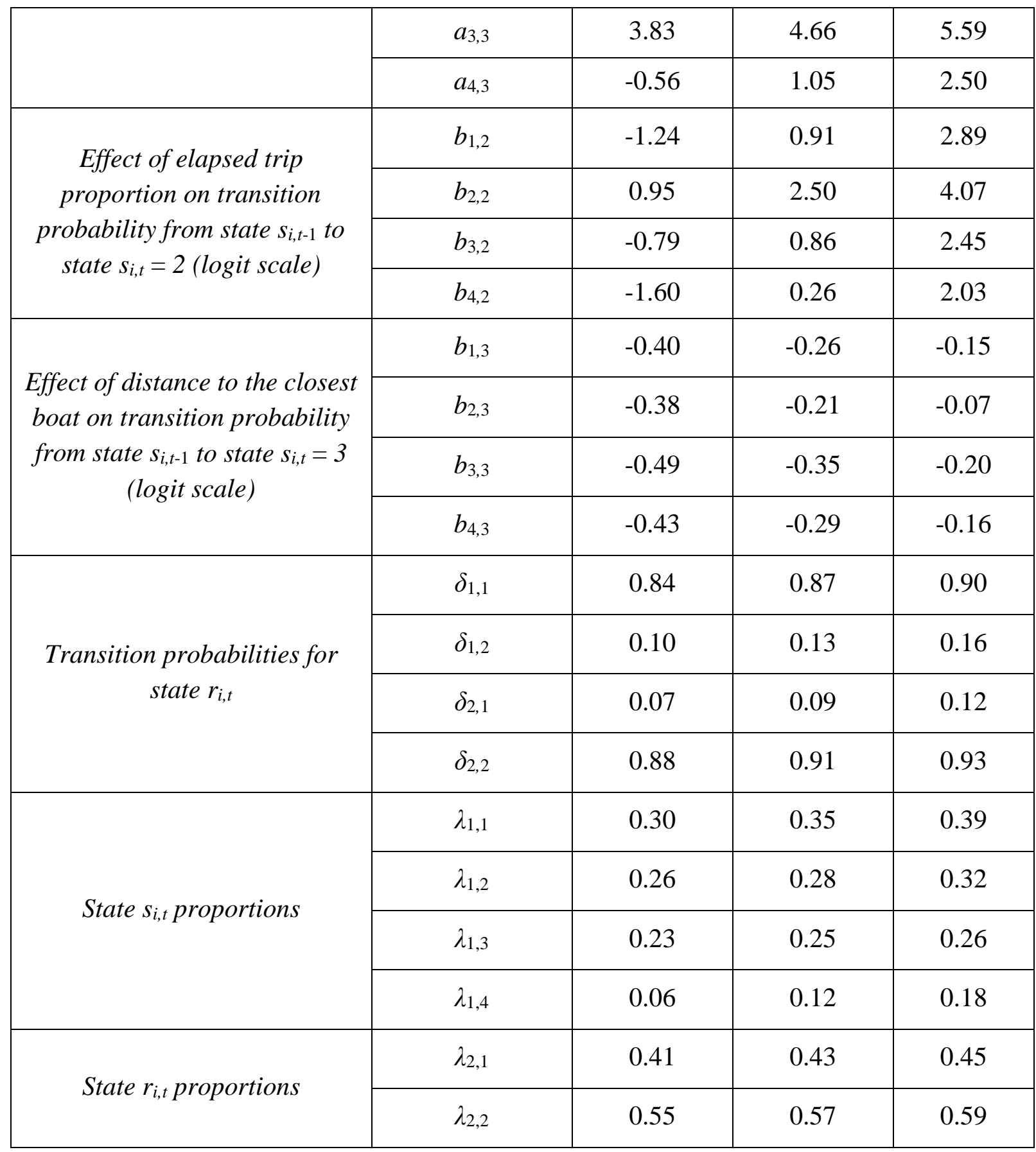




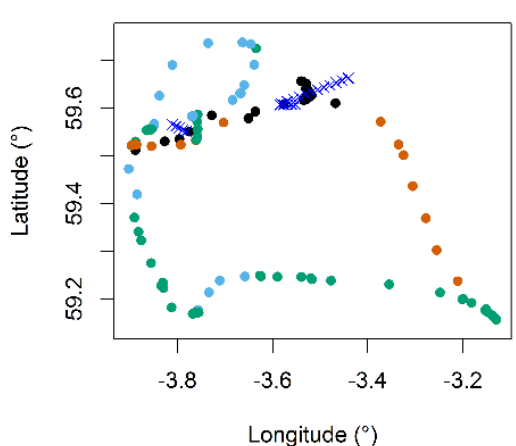

5

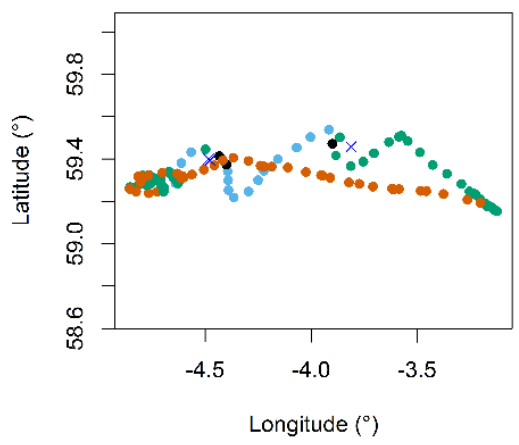

2

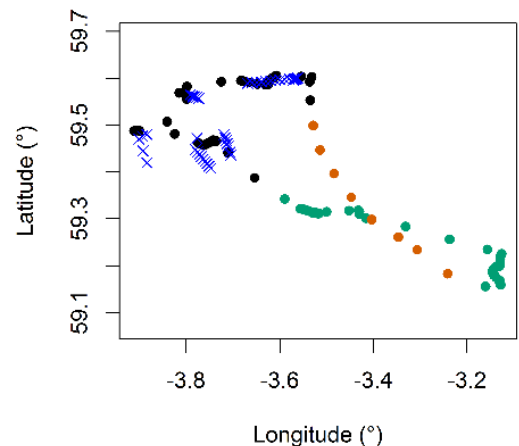

6

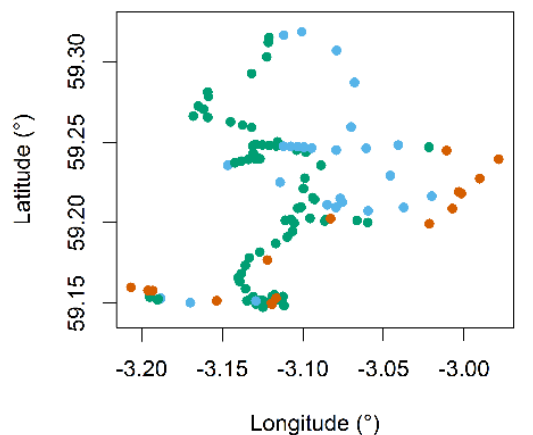

3

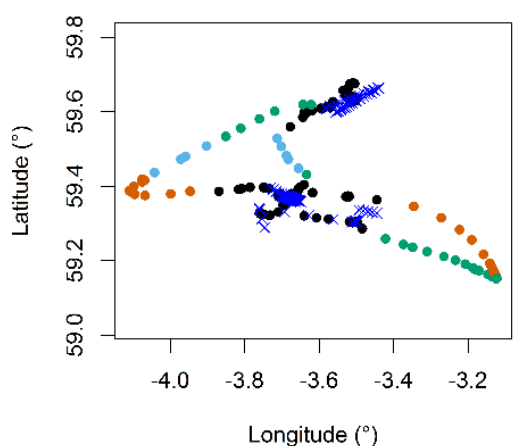

7

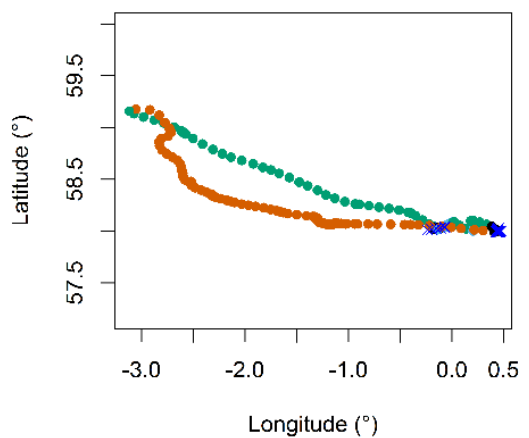

4

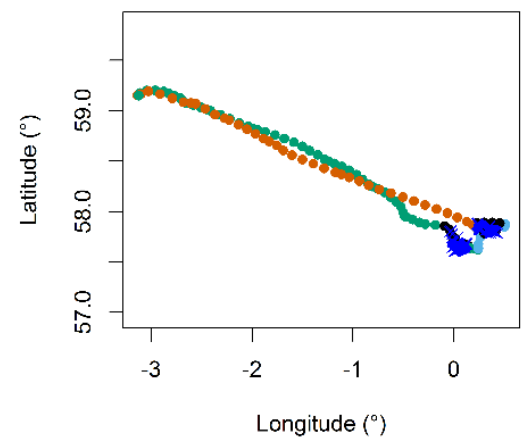

Bird state

- Offhsore

- Colony

- Boat

- Other

Boat

$\times$ Location

Figure S5. Fulmar tracks classified using the model with an additional state representing movement with unknown bearing. An individual can be in one of four states: heading away from the colony towards the offshore region (state 1, green), heading towards the colony (state 2, orange), heading towards the closest boat (state 3, black), or heading towards other patches with no predefined bearing (state 4, light blue). The closest boats are represented as blue crosses. Individual trips are plotted separately. 
Table S9. Posterior estimates of parameters (median and 95\% highest posterior density interval) for a model without the trip-specific concentration of bearing parameters $\varepsilon$. When comparing the state classification under the new model with the classification under the original model, the new model formulation leads to the same state classification in $95.4 \%$ and $99.3 \%$ of locations, for the first and second state process (s and $\mathbf{r}$ ) respectively.

\begin{tabular}{|c|c|c|c|c|}
\hline Description & Parameter & $\begin{array}{l}\text { Lower } \\
(2.5 \%)\end{array}$ & Median & $\begin{array}{l}\text { Upper } \\
(97.5 \%)\end{array}$ \\
\hline \multirow{3}{*}{$\begin{array}{l}\text { Mean distance from closest } \\
\text { boat under state } s_{i, t}\end{array}$} & $\varphi_{1}$ & 3.06 & 3.11 & 3.16 \\
\hline & $\varphi_{2}$ & 3.06 & 3.11 & 3.16 \\
\hline & $\varphi_{3}$ & 0.83 & 0.93 & 1.02 \\
\hline \multirow{3}{*}{$\begin{array}{l}\text { Standard deviation of distance } \\
\text { from closest boat under state } \\
\qquad s_{i, t}\end{array}$} & $\sigma_{1}$ & 0.60 & 0.63 & 0.66 \\
\hline & $\sigma_{2}$ & 0.60 & 0.63 & 0.66 \\
\hline & $\sigma_{3}$ & 0.60 & 0.62 & 0.65 \\
\hline \multirow{2}{*}{$\begin{array}{l}\text { Concentration of observed } \\
\text { bearing }\end{array}$} & $\rho_{1}$ & 0.73 & 0.76 & 0.79 \\
\hline & $\rho_{2}$ & 0.24 & 0.31 & 0.37 \\
\hline \multirow{2}{*}{$\begin{array}{l}\text { Scale of step length } \\
\text { distribution }\end{array}$} & $\alpha_{1}$ & 0.066 & 0.070 & 0.073 \\
\hline & $\alpha_{2}$ & 0.005 & 0.006 & 0.007 \\
\hline \multirow{2}{*}{$\begin{array}{c}\text { Shape of step length } \\
\text { distribution }\end{array}$} & $\beta_{1}$ & 2.07 & 2.29 & 2.53 \\
\hline & $\beta_{2}$ & 0.89 & 0.96 & 1.04 \\
\hline \multirow{6}{*}{$\begin{array}{l}\text { Basal transition probability for } \\
\text { state } s_{i, t} \text { (logit scale) }\end{array}$} & $a_{1,2}$ & -4.58 & -3.79 & -3.07 \\
\hline & $a_{2,2}$ & 0.38 & 1.52 & 2.72 \\
\hline & $a_{3,2}$ & -2.14 & -0.96 & 0.17 \\
\hline & $a_{1,3}$ & 0.17 & 1.39 & 2.60 \\
\hline & $a_{2,3}$ & -0.57 & 1.40 & 3.13 \\
\hline & $a_{3,3}$ & 3.70 & 4.51 & 5.40 \\
\hline \multirow{4}{*}{$\begin{array}{c}\text { Effect of elapsed trip } \\
\text { proportion on transition } \\
\text { probability from state } s_{i, t-1} \text { to } \\
\text { state } s_{i, t}=2 \text { (logit scale) }\end{array}$} & $b_{1,2}$ & -0.32 & 1.28 & 2.81 \\
\hline & $b_{2,2}$ & 0.95 & 2.47 & 3.97 \\
\hline & $b_{3,2}$ & -0.63 & 0.95 & 2.50 \\
\hline & $b_{1,3}$ & -0.50 & -0.37 & -0.26 \\
\hline
\end{tabular}




\begin{tabular}{|c|c|c|c|c|}
\hline \multirow{2}{*}{$\begin{array}{c}\text { Effect of distance to the closest } \\
\text { boat on transition probability } \\
\text { from state } \text { si,t-1 }_{\text {to state } s_{i, t}=3} \\
\text { (logit scale) }\end{array}$} & $b_{2,3}$ & -0.36 & -0.22 & -0.09 \\
\hline & $b_{3,3}$ & -0.50 & -0.36 & -0.22 \\
\hline \multirow{4}{*}{$\begin{array}{c}\text { Transition probabilities for } \\
\text { state } r_{i, t}\end{array}$} & $\delta_{1,1}$ & 0.84 & 0.87 & 0.90 \\
\hline & $\delta_{1,2}$ & 0.10 & 0.13 & 0.16 \\
\hline & $\delta_{2,1}$ & 0.07 & 0.09 & 0.12 \\
\hline & $\delta_{2,2}$ & 0.88 & 0.91 & 0.93 \\
\hline \multirow{3}{*}{ State $s_{i, t}$ proportions } & $\lambda_{1,1}$ & 0.41 & 0.44 & 0.46 \\
\hline & $\lambda_{1,2}$ & 0.29 & 0.31 & 0.34 \\
\hline & $\lambda_{1,3}$ & 0.24 & 0.25 & 0.26 \\
\hline \multirow{2}{*}{ State $r_{i, t}$ proportions } & $\lambda_{2,1}$ & 0.41 & 0.43 & 0.45 \\
\hline & $\lambda_{2,2}$ & 0.55 & 0.57 & 0.59 \\
\hline
\end{tabular}


Appendix S6. Reformulation of the model with larger priors for the state-dependent distribution of distance from the closest boat.

The priors for the state-dependent means of the lognormal distance from the closest boat $(\varphi)$ and associated uncertainties ( $\boldsymbol{\sigma})$ were chosen based on the observed distribution of distances in the data exploration (Table S2). To test whether these priors had an effect on the uncertainty of the posterior, we ran a new model where we decreased the precision of the Normal priors for $\varphi$ by an order of magnitude (from 1 to 0.1 , corresponding to a change in standard deviation from 1 to approximately 3.2) and increased the range of the flat Uniform priors for $\boldsymbol{\sigma}$ by an order of magnitude (from 1 to 10 ), i.e.:

$$
\begin{aligned}
& \varphi_{1}=\varphi_{2} \sim \text { Truncated Normal }(3,3.2)\left[\varphi_{3},\right] \\
& \varphi_{3} \sim \text { Truncated Normal }(1,3.2)[0,] \\
& \sigma_{1}=\sigma_{2} \sim \text { Uniform }(0,10) \\
& \sigma_{3} \sim \text { Uniform }\left(0, \sigma_{1}\right)
\end{aligned}
$$

This did not change the results. In summary, the new posterior medians for parameters $\boldsymbol{\varphi}$ and $\boldsymbol{\sigma}$ (and 95\% highest posterior density interval) were:

$$
\begin{aligned}
& \varphi_{1}=\varphi_{2}=3.1(3.05-3.15) \\
& \varphi_{3}=0.90(0.80-1.00) \\
& \sigma_{1}=\sigma_{2}=0.63(0.60-0.66) \\
& \sigma_{3}=0.63(0.60-0.66) .
\end{aligned}
$$




\section{References (Supplementary information)}

McClintock, B.T., King, R., Thomas, L., Matthiopoulos, J., McConnell, B.J. \& Morales, J.M. (2012). A general discrete-time modeling framework for animal movement using multistate random walks. Ecological Monographs, 82, 335-349.

McClintock, B.T., Russell, D.J.F., Matthiopoulos, J. \& King, R. (2013). Combining individual animal movement and ancillary biotelemetry data to investigate population-level activity budgets. Ecology, 94, 838-849.

Michelot, T., Langrock, R., Bestley, S., Jonsen, I.D., Photopoulou, T. \& Patterson, T.A. (2017). Estimation and simulation of foraging trips in land-based marine predators. Ecology, 98, 1932-1944.

Michelot, T., Langrock, R. \& Patterson, T.A. (2016). moveHMM: an R package for the statistical modelling of animal movement data using hidden Markov models. Methods in Ecology and Evolution, 7, 1308-1315.

Morales, J.M., Haydon, D.T., Frair, J., Holsinger, K.E. \& Fryxell, J.M. (2004). Extracting more out of relocation data: building movement models as mixtures of random walks. Ecology, 85, 2436-2445.

Torres, L.G., Thompson, D.R., Bearhop, S., Votier, S., Taylor, G.A., Sagar, P.M. \& Robertson, B.C. (2011). White-capped albatrosses alter fine-scale foraging behavior patterns when associated with fishing vessels. Marine Ecology Progress Series, 428, 289-301. 